Portland State University

PDXScholar

Winter 3-7-2018

\title{
Framing Race and Blame in the Media: a Case Study on the Chapel Hill Shooting
}

Sara Abdullatif Galadari

Portland State University

Follow this and additional works at: https://pdxscholar.library.pdx.edu/open_access_etds

Part of the Communication Commons

Let us know how access to this document benefits you.

\section{Recommended Citation}

Galadari, Sara Abdullatif, "Framing Race and Blame in the Media: a Case Study on the Chapel Hill Shooting" (2018). Dissertations and Theses. Paper 4251.

https://doi.org/10.15760/etd.6135

This Thesis is brought to you for free and open access. It has been accepted for inclusion in Dissertations and Theses by an authorized administrator of PDXScholar. Please contact us if we can make this document more accessible: pdxscholar@pdx.edu. 
Framing Race and Blame in the Media: A Case Study on the Chapel Hill Shooting

by

Sara Abdullatif Galadari

A thesis submitted in partial fulfillment of the requirements for the degree of

\author{
Master of Science \\ in \\ Communication
}

Thesis Committee:

Cynthia-Lou Coleman, Chair

Jeffrey Robinson

Steve Thorne

Portland State University

2018 


\begin{abstract}
This research examines how racism is hidden and denied by the press, and how blame is attributed to individuals in crime news stories. This research heavily relies of van Dijk's (2015) six discursive strategies to reveal how racism is hidden and denied in the press: positive self-presentation, denial and counter-attack, moral blackmail, subtle denials, mitigation, and defense and offense. Specifically, the Chapel Hill shooting is used as an example of a crime news story for my case study. This study will use framing as the primary method, and critical discourse analysis will be used to guide my interpretations of the frames. Frames are defined by Entman (1993) as texts that select "some aspects of a perceived reality and make them more salient... in such a way as to promote a particular problem definition, causal interpretation, moral evaluation, and/or treatment recommendation for the item described" (p. 52). I will examine words and phrases used when referring to the perpetrator and the victims in the crime story, and examine manifest frames. I begin by explicating terms that my research is founded upon: ideology, critical discourse analysis, race and racism, blame, and framing. Newspaper articles are collected and analyzed for van Dijk's six discursive strategies. The difference between national and regional news coverage is also examined. My findings suggest there are two gaps in van Dijk's six discursive strategies. I propose the addition of two discursive strategies that the press use to deny racism: negative self-presentation and contradiction.
\end{abstract}




\section{Dedication}

To the victims and survivors who are overlooked because of the color of their skin, their beliefs, or their gender. We will change the world, someday. 


\section{Acknowledgements}

Writing this thesis is one of the biggest academic achievements I have made, and I am so honored and humbled that I was able to finally complete this research. I did not get here alone, however, and would like this opportunity to acknowledge some extraordinary people.

I would like to extend my endless gratitude to my thesis committee, who supported and guided me through the entirety of this thesis, and they each have a special role to play: Dr. Robinson, who was my introduction to studying communication. Your enthusiastic teaching and gestures of reassurance inspired my interest in communication as a shy and timid freshman who was taking Introduction to Communication. Dr. Thorne, who was my instructor for one of the most memorable and enjoyable classes I have ever taken as a student. You inspired, encouraged, and helped me develop an idea that led to this research taking place. And finally, Dr. Coleman, who stuck with me from the moment I had taken my first (and toughest) core communication class, COMM 200. You helped me realize that I was capable of achieving so much more than I thought I could. Without your guidance, mentorship, patience, and friendship, I would not have pushed myself to complete nearly as much as I have. Thank you, Coleman.

I would also love to give a special thanks to Dr. Romaniuk, who inspired my interests and guided me to developing the idea that served as the foundation for this research. Your classes were the ones that lit a fire, and the experiences I had working with you were ones that truly stuck with me. 
I would also love to thank the Ministry of Higher Education in the United Arab Emirates, who worked with me to fund my education, and provided me with guidance from excellent advisors. I am also honored to thank the Ruler of Dubai, Sheikh Mohammed bin Rashid Al Maktoum, who teaches and leads by example of loving his people, inspiring humility in light of achievements, instilling the importance and value of education, and inspiring ordinary people to turn into pioneers of the world.

Of course, none of this would be possible without my friends and family. To my best friends, Shahd Khawaja, Kristen Kohashi, and Ashley Yamashiro: your words of encouragement, years of watching each other grow up (whether it was a few miles away or half way across the globe), silly puns, long heart-to-heart conversations, and your sisterhood mean the world to me. To my siblings, Adil and Amer, who were my first friends in my life: we have had a lifetime of adventures, laughter, tears, inside jokes, and memories together. Through thick and thin, we continue to stick by each other, and always will. To my Mom, who has sacrificed and done so much for me: I will never be able to thank you enough. And finally, to my Baba, who no words can do him justice: thank you for always making me believe that I could do anything I set my mind to, and for always believing in me. 


\section{Table of Contents}

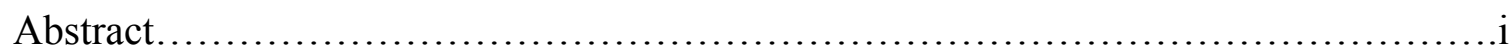

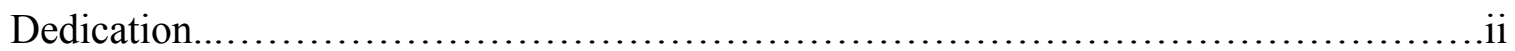

Acknowledgements..............................................................

List of Figures................................................................

Chapter 1: Introduction....................................................

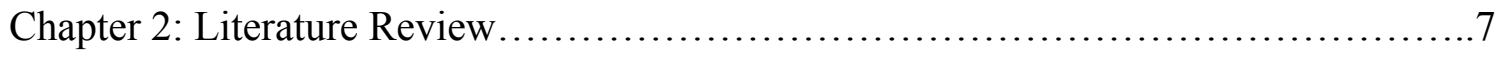

Chapter 3: Methodology....................................................50

Chapter 4: Results......................................................70

Chapter 5: Discussion.................................................... 103

References.............................................................. 116

Appendix A: Newspaper Articles..........................................126

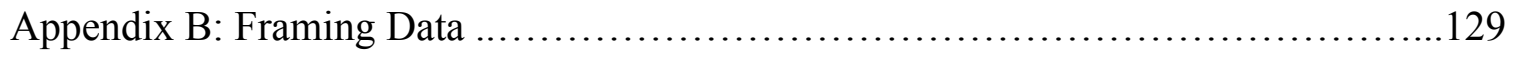




\section{List of Figures}

Figure 2.1. Memes challenging negative portrayals of

Muslims by using negative stereotypes................................ 17

Figure 2.2. Mapping out the ideological square. ....................................32

Figure 3.1. Coding scheme to find frames (i.e., words or phrases)

in news coverage of the Chapel Hill shooting.................................52

Figure 3.2. Number of news articles on the

Chapel Hill shooting in one month........................................67

Figure 3.3. Number of news articles from each news source within

national and regional news coverage. .......................................69

Figure 4.1. Totality of discursive frames....................................... 70

Figure 4.2. Number of instances of words or phrases

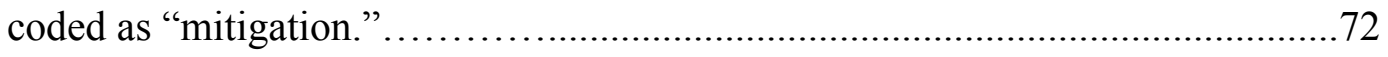

Figure 4.3. Number of instances of words or phrases

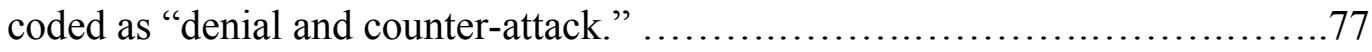

Figure 4.4. Number of instances of words or phrases

coded as "negative self-presentation.".

Figure 4.5. Number of instances of words or phrases

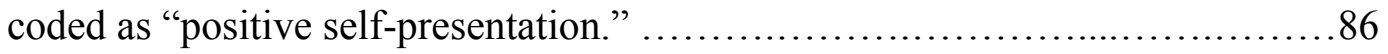

Figure 4.6. Number of instances of words or phrases

coded as "subtle denials." 
Figure 4.7. Number of negative self-presentation frames in national and regional news coverage................................... 95

Figure 4.8. Number of positive self-presentation frames in national and regional news coverage................................... 96

Figure 4.9. Number of denial and counter-attack frames in

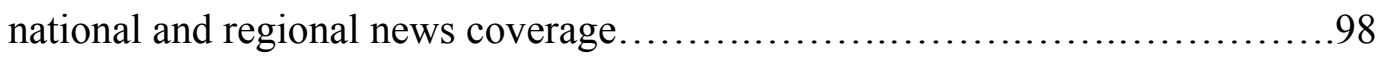

Figure 4.10. Number of mitigation frames in national and regional news coverage..................................... 99

Figure 4.11. Number of subtle denials frames in national and regional news coverage..................................100 


\section{Chapter 1: Introduction}

Envisioning racism conjures up images of individuals who voice bigoted remarks against people of color, overt displays of hateful language and racial slurs, and blatant demonstrations of racial discrimination (Deitch, E., Barsky, A., Butz, R., Chan, S., Brief, A \& Bradley, J., 2003; Kovel, 1970; Tatum, 2014[1997]). While these forms of racism are still prevalent, racism has taken on a different shape. Prior to the Civil Rights era in the 1950's and 1960's, blatant racist behavior was omnipresent (Kovel, 1970; Entman, 1992). While racism in the present-day is still widespread, it is presented more inconspicuously. Coined as "aversive racism" (Kovel, 1970), contemporary racism is directed by social norms that frown upon the notion of racism, thus shaping racist behavior to take a subtler, passive form (Entman, 1992; Tatum, 2014[1997]). Aversive racism occurs when victims of past racial injustices have received sympathy, when the notion of racial equality is supported, and when individuals perceive themselves as unprejudiced. At the same time, negative ideas that are guided by stereotypes and prejudice are still attached to racially marginalized groups (Deitch et al., 2003).

Van Dijk (1992) posits that one of the main properties of contemporary racism is denial through discursive strategies (e.g., "I have nothing against Black people, but..."), among other strategies that help maintain the social status of dominant and marginalized racial groups.

Given that the scope of dominant and marginalized groups in society is a broad one, this thesis aims to examine the way language is used to frame racial dominant and marginalized groups in news media crime stories. This thesis will be primarily guided by 
van Dijk’s (2015) discursive strategies. He argues news media utilize such strategies when discussing race and racial issues, and discursive strategies assign blame to the parties involved in the news stories.

In examining text in newspaper discourse, Richardson (2007) introduces three concepts: 1) Textual forms and content have an inter-related nature such that texts introduced in different ways have different meanings; 2) Levels of analysis. There are two components: the structuring of propositions and the combination, and the sequence of the structured propositions; 3) Texts are multi-functional in nature, and can perform tasks simultaneously. Richardson (2007) argues that these texts simultaneously reveal the physical, social, and mental aspects of the world, and additionally enact the "social relations between participants in social events and the attitudes, desires and values of the participants; and coherently and cohesively connect parts of texts together" (p. 47).

Applying Richardson's arguments to newspaper discourse on race, I posit that newspaper texts reflect the dominant ideology on race, and can influence the public's interpretations of events told through newspaper text depending on the race of the social actors and the parts that they had to play within the news story. Thus, analyzing newspaper text reveals the meaning and the beliefs of the social institutions responsible for the text. Operating under Richardson's assertions of textual analysis in newspaper text will serve to further lead this research on how language is used to place blame on involved parties in newspaper stories.

When examining discourse surrounding racial issues, it is imperative to understand, reveal, and challenge the inequalities unearthed, and comprehend the impact 
of these inequalities within society. Critical discourse analysis is a form of examining the way structures of discourse can "enact, confirm, legitimate, reproduce, or challenge" relations of dominance in society (van Dijk, 2015, p. 467). Critical discourse analysis reveals how language is used when addressing or denying racial stereotypes, which echo certain messages about racial groups, and shows how language can reproduce prejudice through talk and text. Discourse, otherwise known as talk and text, can be examined from the micro-level, which examines how the meanings of sentences are constructed in sentences that immediately follow each other (e.g., language use and verbal interactions, such as everyday conversations), and a macro-level, which examines how discourse is meaningful as a whole (e.g., text and talk in the media, education, and politics) (van Dijk, 1997). Van Dijk (2015) posits that critical discourse analysis can reveal how dominant groups have the ability to influence public discourse and powerful sources of knowledge and information, which are responsible for reproducing stereotypes and prejudices in public discourse. Moreover, applying critical discourse analysis to discourse in news media allows for examining the way news is framed: examining how sentences are structured, the use of active or passive voice, or what information is included or omitted, impact the way news is delivered about marginalized and dominant racial groups (Richardson, 2007; van Dijk, 2015). Weaving critical discourse analysis's application to discourse on race and news media discourse together will serve as the foundation for the methodology in this thesis.

The purpose of this study is to examine discourse surrounding race and crime in news media. Given that the scope of this subject is a broad one, I will use a case study of 
a single crime story to exemplify my research. I will examine news stories surrounding the event of a shooting that occurred in Chapel Hill, North Carolina, and investigate the way race and blame attribution is framed in the associated news crime stories. The frames will be informed by critical discourse analysis, which will be further defined in the literature review. The goal of this research is to add to the literature on racial representation in news media, examine how blame is attributed to people in news stories depending on whether they belong to the racially dominant group or racially marginalized groups, and enact social change.

The rest of this chapter will give an overview of the news crime story that will be used as the case study for this research. Chapter 2 showcases the explication of racism, framing, and blame, as well as a review of existing literature on the portrayal of race and racial issues in the media, attribution of blame through language, and framing. Chapter 3 delves into the methodology utilized for this research.

\section{Case Study: Chapel Hill shooting}

Tragedy struck the community in Chapel Hill, North Carolina on the evening of February 10, 2015, when three members of a family were found dead in their apartment, each of them with a fatal bullet wound on their heads. The perpetrator, 46 year-old white male Stephen Hicks, later turned himself in to the police, and the authorities seized thirteen firearms that were found in his home, among them the murder weapon. The victims killed were 23 year-old Deah Barakat and 21 year-old Yusor Abu-Salha, as well as Yusor's sister, 19 year-old Razan Abu-Salha, all of whom were Muslim ArabAmericans. Reports of the Chapel Hill shooting gained attention on social media, and 
were followed by coverage in several news outlets. While the police investigating the shooting claimed that the events transpired over a parking dispute, many voiced their concern that given the ethnicity and faith of the victims, that the shooting was a hate crime, especially since the events occurred "in the wake of a disturbing rise in especially threatening and vitriolic anti-Muslim rhetoric and activities" (Interfaith Center of New York, 2013). Much of the coverage focused on the victims and their livelihoods, contrasting with short snippets about the killer, which covered his three failed marriages, discussions on gun rights, and statements from his previous wives about his behavior.

This case struck my attention in particular with the way language was used in the coverage of the shooting, and the media's approach to labeling the victims and the killer. News stories can be powerful influencers in today's society, having the ability to give readers access to different stories and narratives that occur in different parts of the world. The way news stories are framed has the ability to set the public's idea of what to think about, and may influence the interpretation of the news story, thus potentially shaping the public's ideology about different aspects of the world, such as race and gender (Tatum, 2014[1997]). The term ideology here refers to the "images, concepts, and premises which provide the frameworks through which we represent, interpret, understand and 'make sense' of some aspect of social existence" (Hall, 2000). Framing in news stories is tied to bias, and orients stories by accounting for "organizational and modality constraints, professional judgments, and certain judgments about the audience" (Scheufele, 1999, p. 105). Scheufele further argues that the media influence the public's ideology about social constraints like race and gender. 
In discussing biases in the media, it is important to examine power and knowledge in society, and the role they play within the media. Dominant groups in society have social power in organizations, groups, and institutions, thus enabling them to have more control over other groups in society than marginalized groups. Having more social power indicates having more control and power over the actions and thoughts of another group, which contributes to the classification of groups as either dominant or marginalized. Employing news media as a means of conveying these messages disseminates the dominant ideology to the public, making the dominant ideology the norm. Dominant groups are given access to resources, culture, social capital, and power over the public discourse and communication thus having control over the media's narrative of news stories (van Dijk, 2015). 


\section{Chapter 2: Literature Review}

As this study seeks to explore racial representation in news media and attributions of blame, this chapter will provide contextual understanding for the study by providing an overview of critical discourse analysis. The main factors in this thesis will also be defined and explicated: ideology, racism, blame, and framing (Chaffee, 1991). An overview of news media portrayals of race and racial issues will be discussed, followed by a thorough explanation of van Dijk's (2015) outline of how the press denies racism. This will be tied to the attribution of blame in news media, along with an in-depth description of Richardson's (2007) newspaper textual analysis principles. Literature on framing will be presented, ending with an overview of how race is framed in news media.

\section{Defining Ideology}

Ideology is a broad term that has its meaning disputed over different social science scholars (Gouldner, 1976). Van Dijk (1995) asserts that ideologies are the basic framework of how people organize the collective social cognitions of social groups, organizations, and institutions. Social cognition is defined as the structure of "mental representations" that are fundamental to discourse and behavior, and the societal stances and interests of social groups (van Dijk, 1995). Van Dijk's conception of ideology allows for establishing a link between studying macro-level groups, such as social institutions and structures, and micro-level analyses of individual interactions and discourse. For example,

Van Dijk posits that sociocultural knowledge that is shared by members of a particular social group, culture, or society, is part of how ideology is formed across the 
collective social cognitions; ideologies are the overall abstract "mental systems" that establish socially collective attitudes. Members of social groups can share beliefs, opinions, and attitudes that are structured into social attitudes. For example, feminists can share attitudes about abortion rights, gender equality in the workplace and wages, and forms of discrimination and over-sexualization by men. These attitudes can be structured internally and jointly connected to fundamental principles that define a feminist ideology. In the same way, racist ideologies operate with shared beliefs, opinions, and attitudes that are structured into social attitudes that form their racist ideologies.

Ideologies are slowly adopted by members of a group or culture through longterm processes of socialization and other forms of social information processing. Van Dijk argues that since ideologies are a system of principles that structure social cognitions, they are assumed to control the social reproduction of the group through the minds of the group's members. Ideologies represent the elementary social characteristics of a group, e.g. "identity, tasks, goals, norms, values, position, and resources" (p. 18). Ideologies are also self-serving, thus are organized by the aforementioned social group characteristics. Van Dijk provides the example of White racists, who characterize society by a conflict between Whites and people of color; White racists perceive people of color as a threat to their identity, goals, positions, values, and resources. This is also conveyed by representing issues between the Whites and people of color as "us versus them," effectively othering people of color. The othering of people of color is further maintained by associating positive aspects with the Whites and negative aspects with people of color. 
Ideologies of different social groups are established by selections made by the social group on what social values and issues are relevant. Comparing the examples of feminist ideologies and White racists reveal that feminists choose and assign importance to values that they align feminism with, such as equality, independence, and autonomy; on the other hand, the White racists assign value to the superiority of their social group (inequality), self identity, and the importance of their social group.

Hall (1981) refers to ideology as the "images, concepts and premises" which establish the frameworks through which people interpret and make sense of some aspect of reality (p. 104). Hall argues that ideologies are not made up of isolated and distinct concepts. Rather, ideologies consist of the expression of different elements into an idiosyncratic set, depending on the particular ideology of different social groups. For example, in liberal ideology, the word "freedom" is linked to the idea of individualism, while in socialist ideology, the word "freedom" is a shared state which is dependent on the "equality of condition" (Hall, 1981, p.104). The same word or idea is propositioned differently depending on the logic of the different ideological discourses. Hall claims that one of the issues of ideology is interpreting different elements within different ideologies, which results in generating different meanings. This extends beyond cognitive activity and into the real world through social behavior, actions, discourse, and language. Hall asserts that language is the primary tool for ideologies to be shared, thus an individual making ideological statements can share their ideology through the discourse that he or she uses. 
Hall asserts that while individuals can make ideological statements, ideologies are not the product of the individual's consciousness or objectives. Rather, the individuals express their intentions within ideology (Hall, 1981). Ideology forms part of the social establishments and conditions that individuals are born into. Individuals have to then communicate through the ideologies that are already present and active in their society, which equips them with the ability to understand social relations and their place within them. Thus, the transformation of ideologies is a collaborative process and practice, rather than an individual one. Hall argues that the process of ideology works unconsciously in the individual; they are not necessarily aware that they have been shaped by the ideologies present in their society, and are most effective when individuals construct statements about the world that has underlying ideological foundations. Ideological statements can be descriptive statements about how the world works, common sense, or assertions that appear as universal truths. Examining statement, "boys will be boys," yields an insight on how ideology functions. This statement is grounded in what some people believe is the nature of femininity and masculinity, rather than attribute the statement as a product of the social, historical, and cultural construction of femininity and masculinity. Similar to gender, race is perceived as an attribute founded in nature. Thus, racist statements can be founded in racist ideologies, since the attributes of a person's race are perceived as truths founded in nature (Hall, 1981).

\section{Critical Discourse Analysis: An Overview}

Critical discourse analysis is a form of analytical research that essentially examines the way social-power is abused, and how inequality between social groups are 
"enacted, reproduced, legitimated, and resisted by text and talk in the social and political context" (van Dijk, 2015). Critical discourse analysis was founded in critical linguistics, which is a sect of discourse analysis that explains why and how certain discourses are produced (Fairclough, 2013). Critical linguistics dictates that discourse reflects social processes and structures, and sustains, combines, and replicates existing social structures (Teo, 2000). Furthermore, discourse is a product and a reflection of social processes, and contributes to the production and reproduction of social processes. Social processes here means the interactions of individuals and groups, and how relationships and behavioral patterns are adjusted and readjusted through social interactions with other individuals and groups (Bardis, 1979). Researchers who perform critical discourse analysis tend to aim for understanding, exposing, and challenging social inequality (Wodak \& Fairclough, 2004). A widespread misconception of critical discourse analysis is that there is a certain method of performing discourse analysis; there is no particular method for critical discourse analysis. Rather, it is an analytical practice that can utilize any of the methods that are used in the humanities and social sciences. For this thesis, critical discourse analysis will be performed through text analysis and analyzing frames used in news stories.

It is imperative to define what is meant by "critical" and "discourse," in critical discourse analysis. The word "critical" in critical discourse analysis signifies the importance for researchers to examine the ideological foundations of discourse that are so ubiquitous, that over time, those ideological foundations in discourse are perceived as common sense or beliefs, or in other words, become naturalized. Operating under 
"critical" goals allows for researchers to clarify and understand the naturalizations of ideological foundations in discourse, and allows for examining the effects of discourse on individuals and social groups (Fairclough, 1989). Critical discourse analysis explores the “crucial role played by deeper, larger social forces which exist in a dialectical relationship with the discourse" (Teo, 2000). In other words, society shapes and is shaped by discourse, and vice versa.

Applying a critical approach to analyzing discourse typically draws data from conversations from situations where there is a power disparity between the parties engaging in communication; one party holds more authority over another party, thus skewing the balance of power and potentially influencing or controlling discourse, e.g., reports from the news media, and job or political interviews. Data for critical discourse analysis are also drawn from instances where manipulative strategies are used to convey or obscure information from the public, but are conveyed in what appears to be a neutral stance. For example, Richardson (2007) examines the way newspapers portray the same acts committed by British soldiers and Iraqi soldiers, and finds that the Iraqi army, the out-group in the news story context, was portrayed in a much more vicious manner than the British army, regardless of the fact that the story was describing similar acts committed by both parties. The British soldiers were briefly mentioned in the newspaper excerpt, and were described as being "poised." On the other hand, the Iraqi soldiers were the main focus of the article, with the words "bloodbath, rioting, hand to hand battles, machine guns, revolt," used to describe their actions (Richardson, 2007, p. 48). 
Moving to examine the term "discourse" in critical discourse analysis, "discourse" refers to the different ways meaning is constructed and communicated (Torfing, 2005). Forms of discourse expand to include newspaper text, everyday conversations, speeches, and entertainment media, all of which contributes to the construction of meaning and ideology (van Dijk, 2014[1992]). These different forms of discourse inform critical scholars on the way society functions and the construction of ideology. Guided by the newspaper representation of society, researchers can observe its projection onto society. For example, this research examines a case study of news stories pertaining to a shooting, where the perpetrator was a member of the dominant group (i.e. White), and the victims were members of a racially marginalized group (i.e. Arabs). Examining a collection of newspaper articles on the event will reveal the discourse on newspaper representation of their respective racial groups, thus informing the research on what society and construction of racial ideologies looks like.

Van Dijk (2014[1992]) and Gramsci (1971) assert that critical discourse analysis addresses how discourse does ideological work. Ideology is embedded in discourse, and language is the medium through which ideology is communicated, shared, and reproduced (Hall, 1981). Since language is a means of social construction, investigating the way language and discourse are enacted in interactional and social contexts allow researchers to examine the underlying ideological premisses of discourse, and uncover the social meanings articulated in language and discourse (Hall, 1981; Teo, 2000; van Dijk, 2014[1992]). Critical discourse analysis aims to reveal social, cultural, and political ideologies that have become established as "common sense" in discourse, as well as 
expose the construction of power structures through discourse. This is exemplified in research studying racism. Rather than perceiving racism as simply prejudice and misinformation on the out-group, racism is seen as a system of advantage based on race; racism is a power structure that serves to maintain the racially dominant group's expedient position over racially marginalized groups (Tatum, 2014[1997]; van Dijk, 2015). The prejudice and discrimination that are associated with racism extends into social structures and institutions, which marginalize minority racial groups, and thus benefiting the dominant racial group. For example, White people have easier access to social resources, such as housing, jobs, education, bank loans, etc. than other racially marginalized groups (Tatum, 2014[1997]). Thus, racism is a primary factor in maintaining power structures in society that have been entrenched by social and historical constructions, and is maintained through racist ideologies shared through discourse and language. In order to comprehend the weight of discourse and ideology in racism, an explication of race and racism is provided.

\section{Explicating Race and Racism}

Tatum (2014[1997]) asserts that there are some people who believe that racism is a thing of the past. It is not that racism does not exist in our society; rather, there are just different displays of racism that have different levels of subtlety. At a surface level, racism is defined as discrimination and prejudice against people of different races or ethnic backgrounds, which is further fueled by racist stereotypes (Berman \& Paradies, 2010; Bivens, 1995; Bonilla \& Rosa, 2015; van Dijk, 2015). Although this definition reflects components of racism, it does not take into account how racism is present, or 
how it functions in society. Racism is often used interchangeably with prejudice in the literature. While the two terms are heavily intertwined, they are distinct from each other. Limiting the definition of racism by equating the definition of racism to the definition of prejudice does not provide enough of an explanation as to why race is prevalent in society. Tatum offers an alternative definition of racism: "a system of advantage based on race" (Tatum, 2014[1997], p. 128). This shifts the attention from the behavior of racism to its fundamental way of prevailing in society. Examining this from a critical perspective, it is crucial to take into account the origin of the word, who created the definition, and who benefits from that definition. By altering the definition to include that it is embedded in a system that benefits from racism, it shifts the attention to how and why the behavior is being performed to why the behavior is still prevalent in society.

Tatum's definition reveals the forms of oppression embedded in a system that works from macro-levels, like cultural messages, institutional policies and practices; this trickles down into the micro-level, like the beliefs and actions of individuals, and personal ideologies formed by racial prejudices (p. 128). This demonstrates that even though one might not actively embrace or perpetuate prejudicial thinking, members of the dominant group still benefit from and protect their racial advantages. For instance, a person from the racially dominant group (i.e., White) might be actively protesting against racism against minority groups, therefore demonstrating that he or she is rejecting the idea that one race is superior over another, the person from the racially dominant group still benefits from the racism that is systemically embedded in society, such as having easier access to resources, housing, jobs, schools, etc. because they do not belong to 
racially marginalized groups, and therefore do not have stereotypes or prejudice associated with their race (Tatum, 2014[1997]). This thesis will operate under Tatum's (2014[1997]) definition, which is "a system of advantage based on race" (p. 128).

Hall (1981) distinguishes between overt and inferential racism. Occasions where obvious and favorable coverage is awarded to "arguments, positions and spokespersons who are in the business of elaborating an openly racist argument or advancing a racist policy or view" are considered displays of overt racism (Hall, 1981, p. 106). Conversely, inferential racism includes instances of seemingly normalized factual or fictional depictions of events and situations regarding race. These depictions operate on racist ideas that have a set of unquestioned assumptions embedded in them, which allows for racist statements to be made without calling attention to the racism on which the statements are founded. For example, humor can be used as a tool to introduce the topic of race and racism in conversations and entertainment (Barnes, Palmary \& Durrheim, 2001). Although humor has been used to combat instances of racism, it also has the ability to facilitate racist speech (Barnes et al., 2001; Tatum, 2014[1997]; Zimbardo, 2014). The following set of memes serve as the perfect example. A meme is defined as the spread of ideas that are depicted through "written text, image, language 'move,' or some other unit of cultural stuff" (Knobel \& Lankshear, 2007, p. 202). Simply put, memes are part of contemporary digital culture that utilizes images, phrases from popular culture, language, or a mixture of the aforementioned elements, to communicate an idea or message. There are different genres for memes, humor being one of the popular meme genres (Miltner, 2014). The following set of memes depict a stereotypical image of a 
Muslim man accompanied by a line of text above the image that conveys negative stereotypes of Muslims, followed by a line of text below the image of the Muslim man that when added together in a coherent sentence, dispels the blatant stereotype about Muslims.

Figure 2.1. Memes challenging negative portrayals of Muslims by using negative stereotypes.
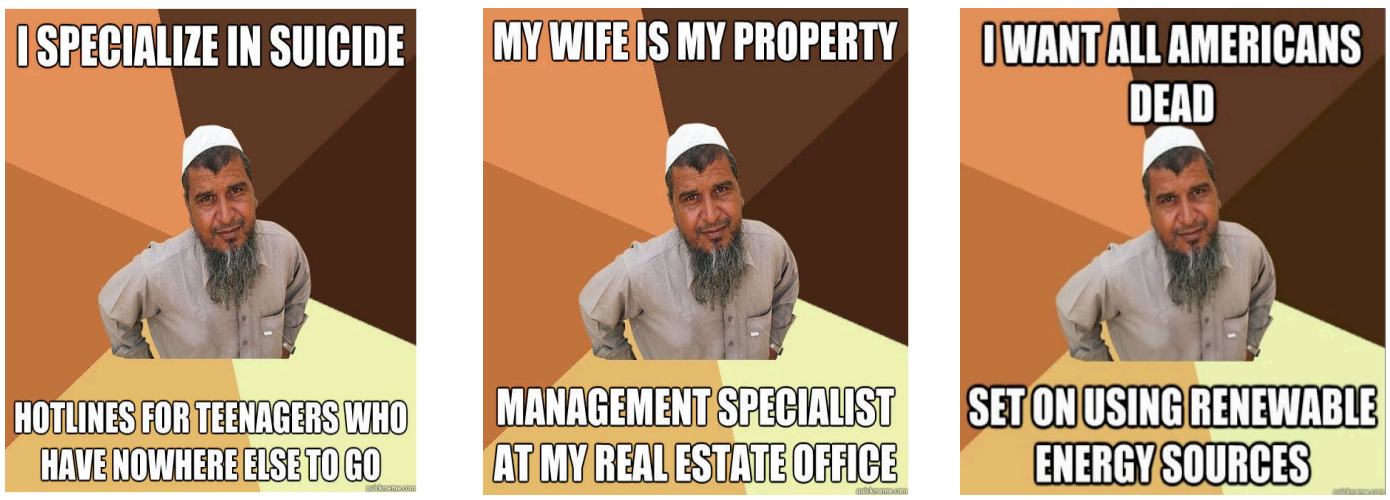

Figure 2.1. Memes challenging negative ideas about Muslims by using humor negative stereotypes to dispel negative stereotypes about Muslims.

While the meme's purpose was to challenge the stereotypical images of Muslims by urging the audience to fully examine the content before passing judgment on someone from this minority group, it certainly reproduces problematic racialized meanings with the presentation of the meme.

Van Dijk (1992) argues that linguistic devices such as humor serve to simultaneously advocate and deny the existence and impact of racism. Using humor to discuss racism gives one the indication that the speaker is not preoccupied with racial issues, thus portraying discussions of race in a lighthearted manner gives the illusion that negative racial comments are innocuous. The subsequent laughter elicited from humorous conversations about race and racism allows the speaker to make racist comments and 
convey racial stereotypes without being labeled a racist, and thus being able to avoid anger or objection to the racist comments because anger or objections are both inappropriate responses to humor (Barnes, et al., 2001). Moreover, humor can be used to create hypothetical instances of encounters with racial marginalized groups, thus allowing the speaker to construct situations in where racial comments about racial differences are warranted, and creating space for racist discourse that serves to further alienate marginalized groups (Jones, 2016). Tatum (2014[1997]) further asserts this behavior as passive racism, which is the subtle instance of racism, with behaviors such as "laughing when a racist joke is told, or letting exclusionary hiring practices go unchallenged, of accepting as appropriate the omissions of people of color from the curriculum, and of avoiding difficult race-related issues" (p. 130).

Philips (1984) examines the effect of racial humor and its ability to perpetuate racist ideas within society. He argues that racial humor, that is, humor that relies on racist stereotypes, and exhibits false or unflattering beliefs about an ethnic group, can incline individuals to evaluate humor as an account of promoting racist beliefs against the targeted ethnic groups. Philips connects his argument to the idea that racial humor based on stereotypes that are founded in truth, which may lead people to question whether the joke was racist or not. He provides the example, "if it is statistically true that Blacks are significantly less literate than Whites, we will be inclined to ask whether it is racist to make jokes about problems created by Black illiteracy" (Philips, 1984, p. 87). This shifts the conversation from social justice issues (e.g., systemic factors that result in low literacy rates for African Americans, such as limited access to resources) to justifying 
ridicule of the racial issue since it is embedded in truth. Racial humor allows for people to use stereotypes to promote racist beliefs, insult, or humiliate marginalized ethnic groups, and the elicited laughter only serves to further legitimize and normalize racism. Inferential racism appears as ubiquitous and unconscious (Tatum [2014[1997]). Hall posits an example of inferential racism in a hypothetical news media story regarding "problems" in race relations. Even if the news story was presented by a broadcaster with good intentions, and maintains neutrality when interviewing individuals for the news story, the news story could end with blaming the radicals_-individuals who push for extreme views - on either side, and claiming that if they had disappeared, the "normal blacks and whites" would be able to learn how to live harmoniously (p. 106). Although the news story was presented with good intentions, the words and images presented in the news story would be punctuated with racism due to the story's premise on the implied assumption that the Blacks were the ultimate source of the problem. This perpetuates the idea that marginalized groups are responsible for the conflicts between racial groups in society, thus inferential racism is replicated in discourse spanning from everyday conversations to news media.

Van Dijk (2014[1992]) claims that racial and ethnic stereotyping is prominent within the dominant group's conversations and institutional talk or text. He argues that this is exemplified in the language used in news stories when discussing marginalized groups, political issues pertaining to race, or instances of discrimination; these discourses reproduce and reiterate negative attitudes towards marginalized groups. Examining this from a critical discourse analysis perspective, the discourse surrounding marginalized 
groups does not exist just to spread negativity and discrimination for the mere sake of discrimination. Rather, the discourse serves as broader "societal, political, and cultural functions" (p.425). Elite groups in politics, academia, and media have much at stake when it comes to maintaining the dominance of their racial group (i.e., White), and have the ability to control public discourse to propagate powerful persuasive measures to assert the dominance and marginalization of other racial groups. In other words, the racially dominant group has the ability to facilitate in the production and reproduction of racism through their control over public discourse.

One of the methods that the elite group employs to maintain its racial dominance in society is the denial of racism. Racial speech is prohibited in most cultural norms, laws, and values, and complying members of society abide by and are aware of those social constraints. Consequently, racist behavior and speech is often met with social sanctions; nonetheless, this does not hinder acts of racism, whether it is overt or inferential. In accordance with social norms surrounding racism, the dominant group tends to deny accusations of racist behavior or speech (van Dijk, 2014[1992]). Denial of racist behavior and speech demonstrates that individuals who break the societal norms surrounding racism by engaging in racist behavior and speech are aware of their breaching the rules. Using disclaimer statements such as "I'm not a racist, but..." exemplifies that the individual is aware that what he or she is about to say has racist premises, thus distancing themselves from any accusations of discriminatory behavior with the disclaimer statement, while having the opportunity to spread negative views on a certain race. It is apparent that sharing overtly racist views has become progressively 
strategic in efforts to abide by social norms opposing explicit expressions of racist views (Billig, 1991; Chiang, 2010).

\section{Portraying Race and Racial Issues in the Media}

Denying racism feeds into creating and maintaining social and racial inequality. It reinforces the ideology that racism does not exist, and therefore is not a problem embedded or present in our society. This undermines efforts to address and rectify racism, and further permeates issues stemming from racism and unequal distribution of resources to marginalized groups. Additionally, denying racism results in the trivialization of everyday acts of racism, whether it is inferential or overt. This serves to preserve the social dominant group's power and dominance in society. Van Dijk (2015) asserts that denying racism can shift blame away from the dominant group and onto the marginalized group, thus framing the dominant group as victims in stories. Van Dijk identifies six methods the press portrays racial issues: positive self-presentation, denial and counter-attack, moral blackmail, subtle denials, mitigation, and defense and offense.

Positive self-presentation is a tactic used to argue against accusations or occurrences of racism within a group. The representatives from the press portray the idea that members of their own group/country are tolerant, or even welcoming, to marginalized groups or immigrants. However, positive self-presentations of tolerance are expressed as tolerance up to a point; if there are excessive breaches of culture or conflicts, they are no longer tolerated. Denial of racism feeds into positive selfpresentation. Van Dijk presents two dimensions to positive self-presentation: social and individual. The individual dimension is attributed to characteristics, informal 
conversations, and interactions between others. For example, people who display some form of racism will deny their actions on an individual level by limiting their actions to themselves, claiming that they themselves are not racist. On a societal level, which includes public discourse (i.e., news media, education, politics), the whole group is included in this statement, claiming that there is no racism in their culture. Societal dimensions are more influential than the individual level due to its ability to reach a larger audience, and thus influence a larger amount of people at once (van Dijk, 2014[1992]).

Teo (2000) uses critical discourse analysis to examine the way racism is embedded in newspaper reports. He analyses news reports on a Vietnamese gang present in Australia, and finds a pattern of stereotyping and "othering" of the marginalized community. Teo reveals the press's racist ideology through their discursive strategies that contributed to shaping the discourse, and aided in maintaining the dominance of the racially dominant group. One of the prominent strategies he found was positive selfpresentation and negative other-presentation, which were specifically located in the news headlines. Teo justifies using headlines for his analysis due to their concise nature and ability to inform and orient their audience to interpret the text according to the way it was framed in the headline. Since news media are organized by their relevance or importance (Cohen \& Young, 1981; Bell, 1991; van Dijk, 1983), readers are able to merely skim the headline in order to obtain a description of what the story is about. Teo (2000) argues that the function of the headline is to construct a "cognitive macro-structure" that functions as a strategic prompt to direct the audience's way of processing and interpreting the story (p. 
14). This also relies on one retrieving relevant background information from long-term memory that is required to interpret the meaning of the text with context (Teo, 2000). He provides the example "Got you... police hit back in the heroin war." This was the headline of a news story regarding past reports of drug-trade in Australia, where gangs such as the Vietnamese gang in question, 5T, operated openly in public, and with disregard of law authorities. Thus, the phrase "hit back" from the headline is meaningful only with prior knowledge, which is the assumption that the news media were operating under. Teo provides several headlines that he analyzed for his research, each of them displaying a theme of violence through the lexical choices made in the language used for the headlines; for example, "Murder witnesses threatened, court told"; "Two gunned down in heroin gang war"; "Street gang's culture of murder" (Teo, 2000, p. 15). In these headlines, the language used places the police in a positive light, and placing the gang members in a negative light.

Denial and counter-attack are forms of denial that occur when the press attacks groups that hold different views than that of the press, while defending groups whose views are in solidarity with the press. The press attacks anti-racists by denying the existence of racism within society, framing the accusations as fabricated and the accusers as paranoid. This is accomplished by presenting racism under the guise of defending the truth, role reversals (e.g., naming others as racists rather than themselves), and reversal of the charges altogether (e.g., naming the anti-racists as the racists for perceiving an event as racist) (van Dijk, 2015). 
Looking to Wasserman's (2010) analysis of news media representation of racism in South African media serves as an example of denial and counter-attack. In 2008, a group of White students filmed Black employees at the Afrikaans University of the Free State, coerced them to take part in degrading actions, such as eating food that one of the students urinated in, and uploaded the video onto social media. The students mentioned in their video that this was in relation and response to the university's attempt to integrate White and Black students into a residence hall. Wasserman examined the media's response to the event, and found that the news media adopt a passive voice when disclosing statements, so that the media commentators could distance themselves from any potentially controversial views presented. In the case of the circulating video of the White students racially abusing the Black university employees, Wasserman observed that the news media's reaction to the video was to deflect anger from the public to a scapegoat, and countered accusations of racism as the Afrikaans's way of blaming Whites, thus turning the accusations of racism around and back onto the marginalized group.

Wasserman's (2010) investigation of the news media's portrayal of the event at the Afrikaans University of the Free State Moral leads us to van Dijk's (2015) third method of the press's denial of racism: moral blackmail. This is where the press frames anti-racist groups or individuals as censoring their ability to report news. The press portrays themselves as the victims silenced by anti-racists, and bullied into not reporting the "truth." The press show that they are being blackmailed morally; they frame the truths as something that must be told, even though the truths may portray negative information 
about a race or ethnicity. The news media poses as a "media-as-mirror metaphor," where the media act as if to simply reflect social reality rather than contributing to constructing social reality (Durrheim, Quayle, Whitehead \& Kriel, 2005; Wasserman, 2010). In other words, the media seek to deny racism by presenting racism as the truth of the world rather than contributing to, and operating under, racist discourse. This contributes to the "individualization of racism," which presents instances of racist behavior as an individualized event that is separate from their society, rather than presenting racism as a product of a systemic problem that media has produced and reiterated (Durrheim et al., 2005; Hall, 1981; van Dijk 2015; Wasserman, 2010).

Subtle denials can reject accusations of racism by relinquishing the blame of being racist by rejecting ownership of information, thus shifting the responsibility of the information to another source. This is accomplished by presenting language within quotation marks, passive language, framing the stories as claims, or claiming that an event labeled as racist "allegedly" occurred. Additionally, denials can be seen as "limited social acceptance"; a person can depict tolerance of minority group so as to appear in accordance to acceptable social norms, but can display disdain for the minority group if they "go too far" (van Dijk, 2014[1992]). Subtle denials act as a form of trivializing racism, or displacing racism outside of the person engaging in subtle denials, and can extend to the person's community, so as to distance themselves from accusations of racism (Wasserman, 2010). For example, the term, "I don't have anything against Blacks, but..." allow speakers to share racist or negative thoughts about another racial group while saving face. Szuchewycz (2000) observes subtle denials of racism in Canadian 
press when examining how Canadians referred to immigrants. Claims that displayed nuances of racism were countered with the "myth of long-standing Canadian tolerance" (Szychewycz, 2000, para. 28). Simply put, accusations of racism were met with claims that racism was not possible in Canada because racism did not exist in Canadian culture; it opposed the narrative of Canadian's ubiquity of tolerance and compassion. In this way, accusations of racism were brushed aside under the guise of positive self-presentation.

Mitigation is the tactic of minimizing an act or the responsibility of the perpetrator, thus redistributing blame when presenting stories of racism (van Dijk, 2015). This is especially present when portraying news stories concerning a member of the dominant group as the antagonist. Downplaying actions, using euphemisms, or other vague terms are strategies employed to minimize an action of the perpetrator from the dominant group, and diminishes the conveyed responsibility. Szuchewycz's (2000) analysis of Canadian news media revealed mitigation strategies in stories featuring Canadians displaying racism; for example, the word "racism," was never explicitly used. Instead, words like "hard-core xenophobes," were used to describe individuals who were described as "only a small percentage of Canadians" (cited in Szuchewycz, 2000). Avoiding the word "racist" in news media is not an uncommon phenomenon (Szychewycz, 2000; van Dijk, 1991). Using the euphemisms like "xenophobe" shifts the attention of readers away from the idea that the basis of the problem is racism and onto the idea that the problem is merely distrust or abhorrence of outsiders and foreigners (Szychewcz, 2000). Additionally, using the word "only" when stating that xenophobes make up "only a small percentage of Canadians" frames the group as distinct from the 
majority of Canadians, thus trivializing significance. This mitigation excludes the seemingly marginalized group of xenophobes from the mainstream community and culture.

Defense and offense occur when the press denies outright discrimination and prejudice, attack anti-racists and associate them with fascists. It is a strategy used to attack anti-racists by marking them as disruptive to society, and that the press is simply trying to defend themselves. The news media attribute hardships that minority groups face to any reason besides racism, and frame racism as an excuse that marginalized groups use to avoid ownership or responsibility of the issues that they operate under. News stories depicting African Americans as criminals, living in poverty, or any other negative stereotype that is associated with being African Americans, often attribute blame to African Americans themselves. Rather than recognizing the systemic social issues that contribute to and construct the rhetoric surrounding racism and social inequality, the media point the blame onto the marginalized group themselves (Entman, 1992; Teo, 2000; van Dijk, 2015). Racism is seen as simply an excuse rather than the root cause for the social issues and inequalities that marginalized racial groups experience. Those who oppose or challenge the news media with accusations of racism painted as overly paranoid, fascists, or racists themselves for perceiving an issue to be racist in the first place (Tatum, 2014[1997]; van Dijk, 2015). 


\section{Explicating Blame}

This thesis aims to examine how blame is attributed to individuals in news crime stories. In order to examine blame attribution, however, blame must be defined. In this context, blame is seen as the individual or party deemed responsible for an event.

Whatley (1996) claims that victims of crime tend to be judged by outside parties as responsible for being on the receiving end of the crime. A theory commonly cited in literature regarding blame is the Just World Theory (Lerner \& Matthews, 1967), which states that having a negative perception of a victim of a crime stems from "overcompensation for a seemingly undeserved act" (Grubb \& Turner, 2012, p. 8). This theory operates under the idea that people are motivated to believe that the world they live in is a fair place, and that people deserve any behavioral outcomes they experience. This provides people with a sense of power and efficacy over their environment. For example, a woman who was the victim of an assault is seen as responsible for her assault under the Just World Theory, because since she lives in a just world, she must have done something to provoke an assault; having a person in society who is capable of assaulting women unprovoked violates the idea of a just world. In order to keep the belief of living in a just world alive, perceiving victims as worthy of unfortunate events happening to them serves to align people's worldview of a fair, just world. Grubb argues that victims of crime, especially rape victims, are typically blamed and disparaged for the role they played in the crime, even sometimes extending the situation to where the victim is held accountable for the crime. Operating under the Just World Theory, the blame is shifted away from the assailant and onto the victim. The victim is assumed to have done 
something provocative in order to evoke a crime committed towards him or her, and therefore is seen as responsible, and deserves to suffer the consequences of the crime.

Shaver (2012) argues that cultural values and individual motives are part of why people blame others. Perceivers are not always aware of their motives for blame attribution to another individual (Lerner \& Miller, 1978; Shaver, 2012). For example, if people believed that the world they resided in is a fair and predictable place, then it would make sense that a person suffering from an injustice must have acted in some way that warranted an unfortunate experience. This typically leads to shifting the blame from the perpetrator onto the victim; even though the real cause of an issue stems from society's structure, the victim is typically assigned blame (Shaver, 2012). For example, in the instance of a man sexually assaulting a woman who was inebriated, the prevalence of rape culture and sexism in society may contribute to the belief that the woman was at fault for being assaulted because she was irresponsible and inebriated, rather than blaming the man for his actions against the woman. Shaver provides another example of a person who is unemployed. While the issue of unemployment can be attributed to the state of typical economic conditions, others blame an unemployed person for their unemployment, and the person's state of being unemployed is attributed to the person's laziness. In the same way, a person who is the victim of a hate crime might have the blame shifted onto him or her rather than attribute the blame to social structures. Operating under the Just World Theory, perceivers of the situation may attribute blame to the victim by claiming that the victim must have acted in a way that elicited harmful behavior as a response. Another response would be to isolate and distinguish the 
perpetrator who carried out the hate crime from society by framing the perpetrator as a member of an out-group (e.g., the perpetrator is mentally ill), thus shifting attention and blame away from social systemic issues, like racism, and preserving the image that the society people reside in is safe, fair, and predictable. Simply put, the hate crime may be framed as an isolated event rather than a result of racism.

This leads us to examine who is framed as worthy of blame and who is exonerated. Examining the literature on how people attribute blame reveals the pattern of people wanting to believe that the world they live in is safe and fair, thus the society and people that they live in must be safe and fair. However, this leads to asking who is perceived as part of society, and who is perceived as an outsider. Being perceived as a part of society means adhering to the dominant culture, which prompts introducing the concept of hegemony. Hegemony is defined as "not simply a configuration of manifestly cultural values or activities, but a system of ideas, practices, and social relations that permeate the institutional and private domains of society" (Anderson, 1988, p. 129). In other words, it is how the dominant group's norms become the overall norm; the culture, beliefs, and values of the dominant group becomes the cultural norm for all social groups, and becomes the dominant ideology.

Having the dominant group's culture shape the dominant ideology rationalizes the social, political, and economic status quo as the natural state of the world, and function to benefit the entire population. In reality, hegemony and the dominant ideology are social constructs that serve to only benefit the dominant group. Hegemony dictates that the norms of the dominant party become so ubiquitous that it becomes known as common 
sense among the entire population (Gramsci, 1971). For example, Babb (1998) recounts her experience meeting a young boy in Peru who wanted to know where she lived. He had assumed she was from Africa, and was surprised when he learned that she lived in the United States. The boy responded by stating that the United States does not have “people like [her] there," and laughed. "His laughter and beliefs reminded me of how thoroughly Whiteness is equated with Americanness" (Babb, 1998, p. 74). By having common sense dictate that the image of an American is a White person, it benefits the racially dominant group by having their identity as a White person automatically associated with the in-group of being an American, thus preserving their dominance over other racial groups in the United States. Following the tenets of hegemony dictates that the people who are perceived to make up society's population are members from the dominant social group. Members from other marginalized groups are seen as outsiders, and therefore different from the mainstream population. Relating this to the Just World Theory, members of society, the dominant social group, are safe and fair, and therefore undeserving of blame. Consequently, the out-group, members of marginalized social group, are framed as worthy of blame. This is often demonstrated in sexual assault cases (Clark, 1998; Shaver, 2012) and racially motivated crimes (Entman, 1992; Teo, 2000; van Dijk, 2014[1992]; van Dijk, 2015), where the blame is shifted away from the perpetrator and onto the victim.

This is further portrayed in the ideological square. The ideological square is a metaphor van Dijk (2014[1992]) utilizes to demonstrate a strategy of framing dominant and marginalized groups in discourse. Essentially, the ideological square engages in 
positive self-presentation and negative other-presentation; it attempts to distinguish between the actions, roles, and positions of the dominant (in-group) and marginalized (out-group) social groups.

\section{Figure 2.2. Mapping out the Ideological Square}

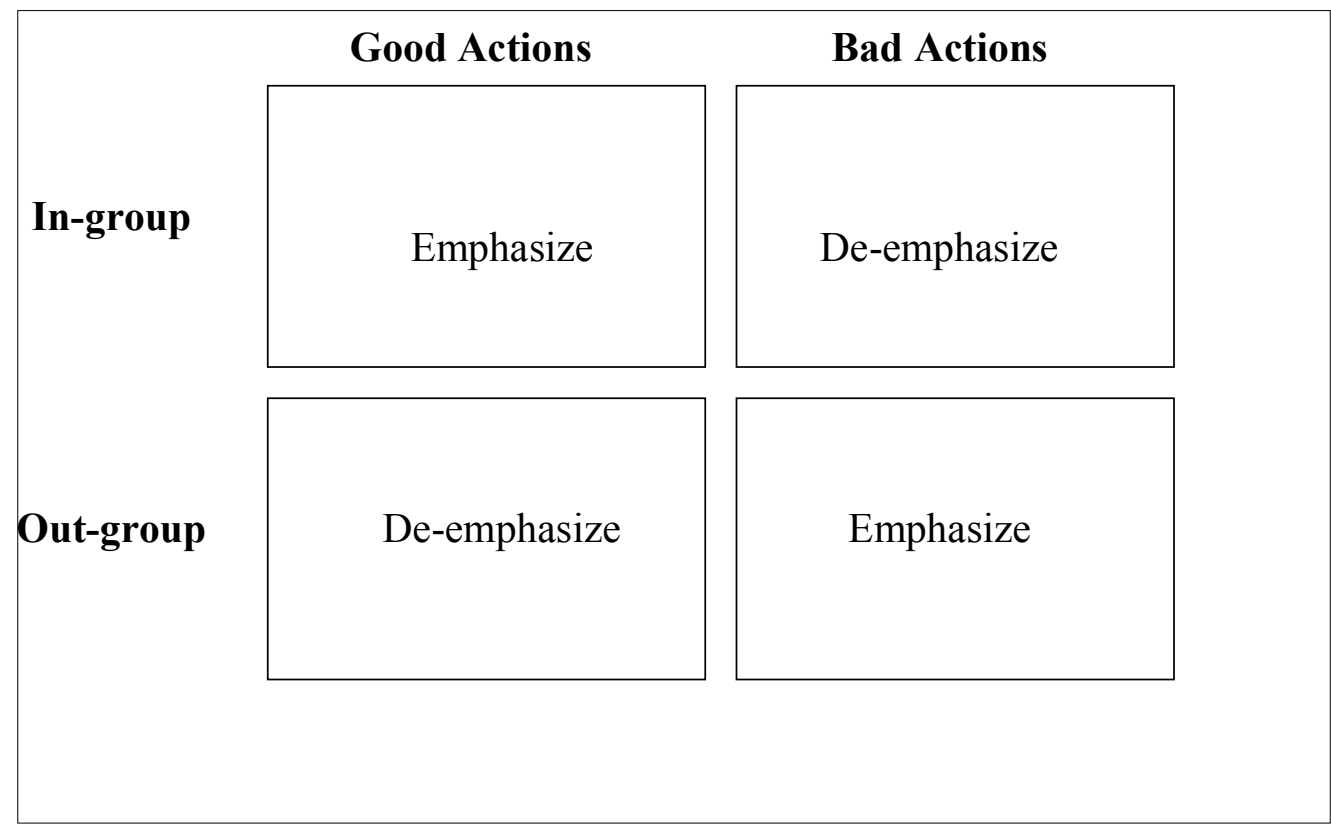

Figure 2.2. A visual representation of the ideological square adapted from van Dijk's (2014[1992]) explanation of the ideological square as a metaphor to describe how the in-group and out-group are framed.

The dominant group utilizes its control over public discourse by polarizing information about each group. This is done by emphasizing the dominant group's positive characteristics and mitigating their negative characteristics, and doing the opposite for the marginalized group (p. 474). In other words, discourse framed through the ideological square presents the opposition of " $u$ s versus them," where we are presented under a positive valence, and they are presented under a negative one (Oktar, 
2001). The ideological square predicts that the marginalized group will be represented negatively, while the dominant group will be presented positively.

In order to exemplify the ideological square, let us examine a news story about a shooting that involved a member from the dominant social group (in this case, a White man) and a member from a marginalized social group (in this case, an Arab man). The framing of the stories would look different, depending on what role each party played in the news story. If the White man, who is a member of the in-group, was the shooter, while the Arab man, who is part of the out-group, was the victim, the ideological square would predict that the actions of the White man would be deemphasized, while the Arab man's actions emphasized. This could take the form of framing the White man's action of shooting as a warranted response to something that the Arab man had done, thus shifting the blame from the White man onto the Arab man; the Arab man could have avoided being shot if he weren't wearing clothes that looked "threatening," and the White man was simply acting out in self-defense. Through the ideological square, the actions of the in-group are mitigated and explained away, while emphasizing the actions of the outgroup, effectively shifting the blame. Additionally, the actions of the White man (ingroup) would be framed as an isolated, individualized incident, rather than having his actions reflected onto his whole social group (Wasserman, 2010). On the other hand, if the roles were reversed, the actions of the Arab man would be emphasized, and his actions would be reflected onto his whole ethnic group.

While these are hypothetical examples, similar portrayals have been observed in news stories where marginalized racial groups were victims of assault or attack from 
members of the dominant racial group. This is demonstrated in the infamous cases of police violence against African Americans that spurred nationwide protests against police brutality and the Black Lives Matter movement: Trayvon Martin, a 17 year-old African American who was fatally shot by a man named George Zimmerman; Eric Garner, a 43 year-old African American, who died from asphyxiation from police officers; and Michael Brown, an 18 year-old African American, who was fatally shot by police officers. Each of the victims was described as displaying suspicious behavior, uncooperative with authorities, or reportedly displaying some form of behavior that warranted an assault. At the same time, the perpetrators, most of whom were members of the dominant group, were framed by mainstream media as doing their civil duties (Bonilla \& Rosa, 2015).

\section{Shifting Blame Through Language}

Richardson (2007) presents the different stages of text analysis that will be implemented in this research. The first stage is lexical analysis, which primarily analyzes the words and phrases used in newspaper text. It is essential to examine the choice to use certain words over others because of the way they convey connoted and denoted meanings. For example, in newspaper texts depicting stories of war, a common strategy is to frame the stories as "us versus them." Provocative words are used when describing the enemy, such as "sneak attacks," while more passive language is used when describing other group, like "preemptive strike." While these two words have the same meaning, i.e., both groups were described as striking the first move in combat, they have very different connotations, thus framing the enemy as evil and deliberate and the other group 
as heroes and strategic. Recall Richardson's (2007) examination of a newspaper excerpt on an attack between British soldiers and Iraqi soldiers. Richardson notes the differences between the descriptions of the two groups; the British soldiers were briefly mentioned, and were described as being "poised." On the other hand, the Iraqi soldiers were the main focus of the article, with the words "bloodbath, rioting, hand to hand battles, machine guns, revolt," used to describe their actions (Richardson, 2007, p. 48). Although the British soldiers and Iraqi soldiers were in the same combative situation, the Iraqi soldiers were at the center of attention, thus glossing over the fact that the British soldiers were engaging in the same behavior, painting the Iraqi soldiers as bloodthirsty and evil.

Another structure of analysis within lexical choice is the act of naming. This is essential due to the way particular names are used for certain people in news discourse, which dictates the way those people are viewed (Richardson, 2007). The names used with describe or name a person can then be used to manipulate the public into associating that person with particular groups. This is referred to as indexical meaning. Naming an individual is a journalist's choice; when reporting on a story, the person must be identified. However, the choice of names used to describe the person, or whether to even name the person at all, is entirely within the journalist's choice. For instance, a person can be identified by aspects other than his or her race; a person can be identified as man, heterosexual, college graduate, millennial, etc. However, a journalist has the ability to index a person's identity by simply choosing to identify the man as Arab, and therefore reducing the individual to mere stereotypes and connotations of being a Arab man while simultaneously isolating him from his other identities. This is referred to as referential 
strategy, which is a powerful tool in instilling an image in the public's eye without ever having to explicitly state anything besides the word "Arab." Referential strategy can be used to serve different purposes that can be psychological, social, or political. In particular, referential strategy can be used to shift blame from one group to another, depending on the way the agent, process, and goal are named and framed.

Another strategy used in newspaper text analysis is predicational strategy. Predicational strategy is defined as the strategy of employing certain words to exemplify the values and characteristics of agents, and assign particular qualities to the agent in question. Using the predicational strategy can establish a relationship between the public and the agent, and can familiarize the person who is focused on in the newspaper text. For example, describing a refugee as a five-year-old doing his homework while sitting at the table with his mother familiarizes the public with him, thus making it easier to identify and sympathize with the boy (KhosraviNik, 2010). On the other hand, the predication strategy can also be used to "criticize, undermine and vilify certain social actors" (Richardson, 2007, p. 53), and place blame on a different agent, which could result in disastrous consequences. For example, Richardson analyzed newspaper headlines describing a girlfriend who provided a false alibi for her boyfriend who committed a murder. Each of the newspaper headlines examined framed her as a liar, and associated her with negative inferences of murderer and killer, e.g., e.g., "Soham liar Maxine Carr", "Soham liar Maxine Carr, the former fiancé of child killer Ian Huntley", “Soham killer's ex-girlfriend" (Richardson, 2007, p. 53). The newspaper articles fail to describe the girl as an independent person, and continuously frame her as the boyfriend's 
possession, e.g., "Soham killer's ex-girlfriend," yet the boyfriend was identified as an independent agent, e.g., "Ian Huntley." This may give the public the belief that the girlfriend is to blame for the actions of her boyfriend who had committed the murders, since the girlfriend is the only one named in conjunction with the murders, while the boyfriend was omitted in sentences mentioning the murders. This can shift the blame away from the killer boyfriend, and focuses the blame on the girlfriend for lying about her boyfriend's actions.

Syntax construction and transitivity is another element in newspaper analysis that is crucial to examine. Transitivity defines the relationships between the roles of the participants that they play with respect to the processes that are described in newspaper text. Transitivity essentially focuses on the way actions are represented in the media, and can alter the way the participants are involved in the process, the process itself, and the circumstances associated with the process (Richardson, 2007). The elements that are in focus in transitivity are the process and participants. Processes entail an action, while participants can either be the agent, who is the person who actually does the process, or the goal, which is the person or thing impacted by the process or agent. For example, in the sentence "John kicked the ball"; the process is the word "kicked," John is the agent, and the ball is the goal.

Similar to the previous methods of newspaper analyses, the way the agents are portrayed in the newspaper text may invoke certain connotations and interpretations depending on the syntactical construction. The involvement of the agents in the process can be altered depending on the way the agents are named and identified in the news 
story. There are four different processes that a sentence can take, depending on the type of verbs that are used: 1) verbal processes, like speaking and shouting, 2) mental processes, like thinking and dreaming, 3) relational processes of the term "being," such as have, seem, be, etc., and 4) Material processes, which are divided into transitive action and intransitive action. The former involves two or more participants, which is the "agent and the object of the action," for example, "The boy played with his brother." The latter is where a single participant performs an action, for example, "The boy ran" (Richardson, 2007, p. 55).

Blame can be shifted from one agent to another through the syntactical construction of the process (Richardson, 2007). Active construction of a process is where the agent comes before the object of the sentence, and the verb is reported in an active form, e.g., Bob (agent) ate (active verb/process) a burger (goal). Passive construction of a process is where the verb is passive, and the object comes before the verb and the agent, e.g., the burger (goal) was eaten (passive verb/process) by Bob (agent). A common theme in newspapers is agent deletion in passive constructions of processes, which removes the agent entirely from the process, e.g., The burger was eaten. Here, blame can be shifted from the agent to a nameless entity, thus erasing the blame from the agent in passive construction of processes, or even shifting the blame onto a different agent.

Clark (1998) illustrates how blame can be shifted through naming and transitivity by examining articles in a newspaper discussing sexual assaults. She examined the way blame is shifted from the attacker to the victim through the use of language, and found a pattern that emerged from her data that tended to follow the trend of shifting blame away 
from the attacker. One of the common strategies that was used to remove blame was making the attacker invisible while drawing attention to the victim. For example, the following headline, "GIRL 7 MURDERED WHILE MUM DRANK AT THE PUB" (Clark, 1998, p. 187). Here, the attacker is the agent, the attack is the process, and the goal is the victim. The headline renders the attacker invisible by deleting him as the agent, thus removing him entirely from the situation. At the same time, the victim is brought to the center of attention, and since the mother's absence in now framed as the cause of her daughter's murder, the blame is moved from the attacker to the mother. Additionally, since the agent is deleted and only the mother and the daughter are mentioned in the headline, a causal relationships is formed between the mother and daughter, strengthening the public's attention and blame onto the mother.

The article describes the mother in unfavorable terms, such as "blonde divorcee," and framing her as an irresponsible person who drank regularly at the pub. Moreover, the article's headline uses an active voice when describing the victim, thus emphasizing the mother's part in the murder of her child. In contrast, Clark also examines another headline, "FIEND STRANGLES ONLY CHILD, 7" (p. 188). The headline uses an active voice when describing the attacker, the agent in this case, as well as naming the attacker with the unfavorable term, "fiend," framing him as sub-human. The strategy of naming the attacker with sub-human descriptors like "fiend" frames the man as an outsider to society, thus making it easier to place blame onto the attacker.

Linguistic analysis of the newspaper text reveals the ideologies of the newspaper's way of viewing and reporting events. In Clark's analysis of sexual assault 
stories in newspaper text, she finds that the newspaper she analyzed had an apparent patriarchal worldview, and portrayed the victims as roles played in a story, and not as real people. The newspaper also uses the strategy of labeling the individuals they see as blame-worthy with sub-human terms, separating them from the humanized individuals in the news stories. This influences the public's view on who is a genuine victim and who is not. Labeling the individuals as sub-human separates them from society, making it easier to place blame onto them. By labeling the attackers as extra-societal, this excuses the society that produced the individuals who turned into attackers. Consequently, Clark argues that the newspaper employs the labeling strategy of shifting blame away from attackers and onto the victims in order to maintain the status quo of society, and reinforcing the idea that the attackers are either outside of society, and thus not part of the in-group, or shifts blame away from the attackers to avoid admitting that the attackers are products of society.

Clark's (1998) critical discourse analysis of the newspaper's portrayal of victims, attackers, and the placement of blame serves as an example as to how the current research will address portrayals of race and blame in the media. Given critical discourse analysis's sociocognitive approach that examines the structure of power by analyzing the relationship between discourse and cognition, critical discourse analysis will be used to analyze the way language is used to place blame on particular group, examine, and challenge inequality within news media stories, and perpetuates the dominant ideology through newspaper text. Thus, the following research question is put forth: 
RQ 1: In what ways does the news coverage of the Chapel Hill murders "deny racism" through the use of van Dijk's six discursive strategies?

\section{Defining Framing}

There are different aspects of framing found within the literature; namely, message framing and cognitive framing. Since this research utilizes message framing in its scope, the literature review will focus solely on message framing. Message framing is essentially the concept of the media's representation of events, which then shapes the language around the events to form an intended interpretation among its audience.

A predominant issue is prevalent among the literature in the framing paradigm regarding is that there is no universal definition of framing. Entman (1993) defines framing as selecting "some aspects of a perceived reality and make them more salient in a communicating text, in such a way as to promote a particular problem definition, causal interpretation, moral evaluation, and/or treatment recommendation for the item described" (p. 52). Entman states the concept of framing is powerful enough to influence the way people interpret messages, and can convince people to perceive certain issues as more important than others. Entman describes how "framing theory shows exactly how frames become embedded within and make themselves manifest in a text, or how framing influences thinking” (p. 51).

Entman (1993) establishes two main components of message framing: selection and salience, and posits that frames call attention to information about the topic in focus, thus elevating the topic by making it appear more salient. Selection refers to the content that is selected and what is omitted in the media, and salience is the way content is made 
"more noticeable, meaningful, or memorable to audiences" (Entman, 1993, p. 53).

Content is made salient by the way it is repeated, placed, or associating the content with symbols that are culturally familiar (Entman, 1993). In other words, frames can bring attention to a subject or interpretation, and make them appear more meaningful and noticeable, raising its salience amongst the public. If there is an increase in salience of a topic, there is a higher chance that people would recall the topic later on, and assign it more importance. For example, Chyi and McCombs (2004) examined news coverage on the Columbine school shooting, a mass shooting at Columbine High School in Colorado committed by two of its own students. There were over 30 casualties, with 12 deaths and 20 wounded, and the event was considered one of the worst mass shootings in the history of the United States (Chyi \& McCombs, 2004). The research's goal was to investigate the way news media make information more salient. The number of news stories that covered the school shooting, and the way the news stories were distributed across the lifespan of the event was measured. By conducting a content analysis of the news stories found in the New York Times, the researchers found that the repeated instances of news stories relating to the event in news media added to its salience, and the emphasis by news media on different aspects of the event over time in order to keep the story alive. Chyi and McCombs's research on salience exemplifies the way topics become more salient by its placement, repetition, or linking them to culturally universal symbols. While the research examined how the story was made salient through framing in the news media, there was no study on its effects on the audience. 
However, some parts of a text may resonate more than others if they fits into one's existing mental schema (e.g., beliefs), thus making the text appear more salient, whether or not the frame's intention was to make that text more salient with its audience. Entman (1993) argues that since salience "lives" within the interaction between a text and its receivers, framing in text does not necessarily guarantee its influence on the public's way of thinking. Additionally, Entman asserts framing's power to select and draw attention to certain aspects of messages: "most frames are defined by what they omit as well as include, and the omissions of potential problem definitions, explanations, evaluations, and recommendations may be as critical as the inclusions in guiding the audience" (Entman, 1993, p. 54). That is, it is just as crucial to pay attention to the information that is omitted than to the information that is included in news media.

Challenging Entman's call for having a single paradigm for framing, D'Angelo (2002) celebrates the fractured nature of framing, arguing that it is because of the fractured nature of framing that research has progressed in the way that is has, likening the accumulated research on framing to a Lakatos perspective (D'Angelo, 2002, p. 871). Lakatos (1974, as cited in D'Angelo, 2002) posits that information regarding a phenomenon is able to develop within an environment, i.e., a research program, that maintains the clash amid different theories, while at the same time providing criteria to assess distinct theories when new data emerge. Similarly, D’Angelo states that knowledge about framing developed due to the way the Lakatos perspective incites researchers to use and cultivate theories about framing through the lens of different paradigmatic perspectives on framing and its effects. 
D’Angelo draws on Entman's (1993) discussion of framing and its conjectures: 1) the communicator, 2) the text, 3) the receiver, and 4) the culture. The first conjecture is the frames' content. News frames are "themes" carried out through different framing devices within news stories. D'Angelo (2002) claims that frames are considered distinct from the actual topic of the news story, since the content of the frame merges text and images with contextual treatment that comes from framing devices. The second conjecture text involves news frames that are one of the primary causes that create different perspectives of reality. D'Angelo argues that no matter what the topic of a news story is, frames serve as a powerful discursive cue that affects its audience's cognition. The third conjecture concerns the notion that news frames are impacted by social and cognitive behaviors that were previously formed; frames live within cognition (e.g., previously held knowledge that serve as mental frames) and the tools that are used within textual frames (Kinder \& Sanders, 1990). The fourth conjecture shapes public discourse about issues regarding politics.

Scheufele (1999) examines framing and bias, claiming that news framing in the media has the ability to influence the audience. However, it is important to note that people are not only affected by material that the media convey. People's prior information is used to interpret issues featured in news media, thus influencing the news media's audience's interpretation of the information through previously formed schemas. Schema is defined as a cognitive framework that helps one organize and comprehend information (Derry, 1996). This is referred to as cognitive frames. Minsky (1975) refers to cognitive frames as preexisting mental structures that allow for organizing and 
interpreting information by reflecting on previously acquired schemas or beliefs. Minsky argues that if a person were to encounter a new situation, he or she would reflect on memories or preexisting information that act as cognitive frames. For instance, if a person walking down a dark alleyway observed an African American man across the street, that person could draw on previous information about news stories concerning African Americans and crime, and associate the African American man on the street with potential danger. Scheufele identifies two concepts of framing regarding presenting and comprehending news: media frames and individual frames (i.e., cognitive frames). Media frames serve as "devices embedded in" discourse, while individual frames are referred to as "internal structures of the mind" (p. 106). Scheufele refers to Entman's (1993) two components of framing - selection and salience - and how the media can provide the public with schemas for interpreting events. Scheufele (1999) agrees with Entman's (1993) notion that framing topics in certain ways can impact the public's interpretation of the events depicted in the media.

\section{Framing Race in the Media}

The Kerner Commission was one of the earlier examinations of the coverage of race within news media in the United States (Report of the National Advisory Commission on Civil Disorders, 1968). In response to the eruption of the five-day long 1967 Detroit riot that primarily involved African Americans, the Kerner Commission was launched to investigate the reasons behind the riots, and collect information to prevent riots from happening in the future. Part of the analysis conducted was examining the role the media played in the riots occurring throughout the community. The Kerner 
Commission found that news channels failed to sufficiently report on the primary problems and events leading up to the riots. Additionally, the Kerner Commission found that the media solely reported from the perspective of White reporters, and failed to report on the history and culture of African Americans in society. Moreover, less than 5\% of U.S. journalists present in news media were African American. Overall, the Kerner Commission found journalism as a backwards profession when it came to hiring, training, and promoting African Americans.

Since the Kerner Commission in 1968, recent studies on news media coverage concerning race has not changed much (Gilens, 1996; Saeed, 2007; Bonilla \& Rosa, 2015). Poole and Richardson (2006) examine the way Muslims are portrayed in news media by conducting a content analysis on news stories surrounding Muslims, and find that the media representations and discourses surrounding Muslims in mainstream media tend to be negative and antagonistic. They reveal that Muslims are typically portrayed as terrorists, cited as terrorist sources, and were shrouded with common themes in the news media: sexual aggressiveness, violence, extremism, fascism, and illegitimacy. Dixon (2008) asserts that African Americans are overrepresented as criminals in news media. Based on the existing literature, it is evident that research on race and news media still find that racially marginalized groups are habitually misrepresented, depicted in stereotypical manners, or simply neglected in the media (Entman 1992; Dixon, 2008; Dixon \& Linz, 2000; Saeed, 2007).

Entman (1994) asserts that while obvious negative stereotypes about race are less prominent in the media, a plethora of more subtle stereotyping and racism against people 
of color exists. For example, Entman examined the way African Americans were portrayed and represented in the news media, and found that African Americans were more likely to be associated with news stories regarding crime. Entman's research revealed that leaders in the African American communities were either portrayed as criminals, being accused of committing crimes, or criticizing the government and its policies. Entman criticized the lack of diversity in the media when it came to presenting information on issues, finding that African American sources were rarely quoted outside of African American issues reported in the news media.

Poindexter, Smith, \& Heider (2003) examined racial representations in news media by conducting a content analysis of local newscasts. Poindexter et al. acknowledge the trend of limited or stereotypical representations of people of color in mainstream news media, but were interested in investigating representation of people of color on more local news media. Poindexter et al. selected content from 26 stations through the years 1987 to 1998 . The researchers coded for race and ethnicity within anchors, reporters, news sources, and perpetrators of crimes that were presented in news stories. Additionally, the racial focus of the news story was coded in the case of stories being reported by a reporter; if over half of the individuals presented in the news story were from one racial or ethnic group, or if one racial or ethnic group was used to demonstrate a story unrelated to race, the primary focus of the instance would be coded as race.

The researchers found that Latinos, Asian Americans, and Native Americans rarely existed as anchors, reporters, subjects, or sources in the news media they examined. Although there were a few African American news anchors or news reporters, 
racial segregation was found; African Americans were only quoted in issues that were seen as African American issues, but were rarely brought in on non-African American issues. Additionally, African Americans were unlikely to be seen as a source for news stories when a story used a single source, and the chances for Latinos, Asian Americans, and Native Americans were even less likely to be seen as expert sources. Simply put, the news media rarely sought out members of minority groups to act as viable sources of information on issues or stories discussed, and even further neglected other marginalized racial groups.

Van Dijk (2014 [1992]) argues that racial and ethnic stereotyping is prominent within the racially dominant group's (i.e., White) discourse (e.g., conversation, institutional talk/text). This filters into macro-level structures, such as the language used in news stories language when talking about marginalized groups, discrimination in interactions, political issues, etc. These discourses reproduce and reiterate negative attitudes towards marginalized groups, thus feeding into the negative stigma and prejudicial behavior and attitudes towards marginalized groups. Conversely, the discourse produced and controlled by the dominant group allows for maintaining its dominance, and has powerful persuasive measures that assert the dominance and submissiveness of groups. This is further portrayed in van Dijk's (2014[1992]) ideological square. Recall that the ideological square is a strategy that engages in positive self-presentation and negative other-presentation, and predicts that the marginalized group will be represented negatively, while the dominant group will be presented positively. 
Many of the events that involve ethnic or racial encounters are experienced through the media rather than the audience's personal antics. Thus, many of the conversations and arguments surrounding crime or differences in culture are read through the press. These reports are seen as evidence of the negative mindsets that the press has about marginalized groups (van Dijk, 2014[1992]). There are problems when actually gathering information for news stories to begin with, since people have limited access to people from different ethnic and cultural backgrounds, and rely on white people from powerful groups; people who are social elites. In addition, minorities are very rarely quoted in news stories.

Since it is against the social norm to display discrimination and racist behaviors, accusations of discrimination are framed as fake and inauthentic. Press stories of discrimination are often embedded within excuses and explanations, and are ultimately dismissed as outlandish accusations. Discrimination is rarely portrayed as a result of racism in news media, due to the understanding that racism is a product of white supremacy, an idea that is rejected by social norms. Therefore, the press denies outright acts of racism, and dismisses people who report racism as intolerant and paranoid (p. 430). 


\section{Chapter 3: Methodology}

This chapter reviews the methodology I implemented in this thesis. I used a case study to examine the way racism is 'denied' using van Dijk's (2015) argument about how the press's discursive strategies deny race and racism. Specifically, I used the Chapel Hill, North Carolina, shooting as an example. According to Yin (1984), case studies investigate phenomena through in-depth contextual analysis of a restricted amount of conditions. Using a case study as a research method allows for investigating data within a particular context. Recall that the shooting was an incident that occurred on February 10, 2015, in Chapel Hill. The perpetrator, Craig Stephen Hicks, was a White man who shot three neighbors: Deah Barakat, Yusor Abu-Salha, and Razan Abu-Salha. Using this incident as a case study will serve as an example of how race and racism are denied in news media. I will focus on the way news stories describe the Chapel Hill shooting. Descriptions here are the foundation of the frames (i.e., words and phrases) that I will examine in news stories on blame attribution and denial of racism. Thus, the following research question is posed:

RQ 1: In what ways does the news coverage of the Chapel Hill murders 'deny racism' through the use of van Dijk's six discursive strategies?

\section{Coding}

This study used framing as the primary method of coding, and critical discourse analysis was used to guide my interpretations of the frames. Frames are defined by Entman (1993) as texts that select "some aspects of a perceived reality and make them more salient... in such a way as to promote a particular problem definition, causal 
interpretation, moral evaluation, and/or treatment recommendation for the item described" (p. 52). I will examine how news stories characterize the shooting, the reasons behind the shooting's occurrence, and the individuals involved in the shooting. Specifically, I will examine manifest frames, specifically looking at words and phrases that were used in news stories about the shooting, the victims, and the perpetrator. I followed Culler's (2011) method of an initial deep reading to get a sense of the news stories. This step allowed for acquiring knowledge through reading narratives, thus gaining knowledge through 'sense-making.'

I examined newspaper articles for van Dijk's six discursive strategies to discover how newspapers described the murders. I then looked for sentences and phrases in context (i.e., frames), and then placed the word or phrase into its respective categories. The data were limited to headlines and the body of text in news articles, and excluded images, image captions, and/or sidebar text.

I established a coding scheme that would allow me to capture the six discursive strategies as a 'frame' (i.e., word or phrase) in the narrative. In the next section, I describe my coding decision rules. I looked for frames, which constitute words or phrases, in news coverage of the Chapel Hill shooting. The frames were informed by van Dijk's six discursive strategies: positive self-presentation, negative self-presentation, denial and counter-attack, moral blackmail, subtle denials, mitigation, and defense and offense. 
Figure 3.1. Coding scheme used to find frames (i.e., words or phrases) in news coverage of the Chapel Hill shooting.

\begin{tabular}{|l|l|l|l|l|l|l|}
\hline ID \# & $\begin{array}{l}\text { ARTICLE } \\
\text { TYPE }\end{array}$ & DATE & $\begin{array}{l}\text { WORD } \\
\text { COUNT }\end{array}$ & PAGE \# & SECTION & $\begin{array}{l}\text { NEWSP } \\
\text {-APER }\end{array}$ \\
\hline \multicolumn{7}{|c|}{} \\
\hline \multicolumn{7}{|c|}{} \\
\hline Positive self-presentation: Manifest positive descriptions of the perpetrator, e.g., 'champion.'
\end{tabular}

Denial and counter-attack: Descriptions of the shooting's motivation that point to reasons other than racism. e.g., 'parking dispute.'

\begin{tabular}{|l|l|l|l|l|l|l|}
\hline MENTION & TERMS & CONTEXT & FRAME & $\begin{array}{l}\text { BLAME } \\
\text { MENTION }\end{array}$ & QUOTED? & $\begin{array}{l}\text { REFERS } \\
\text { TO? }\end{array}$ \\
\hline & & & & & & \\
\hline
\end{tabular}

Moral blackmail: Descriptions of the press claiming they must censor themselves to avoid being labeled a racist. E.g., 'I can't call him a 'terrorist,' because you will think I am a racist.'

\begin{tabular}{|l|l|l|l|l|l|l|}
\hline MENTION & TERMS & CONTEXT & FRAME & $\begin{array}{l}\text { BLAME } \\
\text { MENTION }\end{array}$ & QUOTED? & $\begin{array}{l}\text { REFERS } \\
\text { TO? }\end{array}$ \\
\hline & & & & & & \\
\hline
\end{tabular}

Subtle denials: Casting doubt by prefacing accusations of racism with words such as 'allegedly,' 'claim,' or placing accusations of racism within quotation marks.

\begin{tabular}{|l|l|l|l|l|l|l|}
\hline MENTION & TERMS & CONTEXT & FRAME & $\begin{array}{l}\text { BLAME } \\
\text { MENTION }\end{array}$ & QUOTED? & $\begin{array}{l}\text { REFERS } \\
\text { TO? }\end{array}$ \\
\hline & & & & & & \\
\hline
\end{tabular}

Mitigation: Euphemisms for the shooting: e.g., 'lives cut short,' 'event,' or reattributing the crime to another entity, e.g., 'mental health care, 'gun regulations.'

\begin{tabular}{l|l|l|l|l|l|l|}
\hline MENTION & TERMS & CONTEXT & FRAME & $\begin{array}{l}\text { BLAME } \\
\text { MENTION }\end{array}$ & QUOTED? & $\begin{array}{l}\text { REFERS } \\
\text { TO? }\end{array}$ \\
\hline & \multicolumn{7}{|l|}{$\begin{array}{l}\text { Defense and offense: Directly attacking those who contradict the press, e.g., 'Don't listen to } \\
\text { them, they are just paranoid.' }\end{array}$} \\
\hline MENTION & TERMS & CONTEXT & FRAME & $\begin{array}{l}\text { BLAME } \\
\text { MENTION }\end{array}$ & QUOTED? & $\begin{array}{l}\text { REFERS } \\
\text { TO? }\end{array}$ \\
\hline & & & & & & \\
\hline
\end{tabular}

Figure 3.1. The coding scheme used to find frames (i.e., words or phrases) in news coverage of the Chapel Hill shooting. Each category of the coding scheme is based on van Dijk's (2015) six discursive strategies: positive self-presentation, denial and counter-attack, moral blackmail, subtle denials, mitigation, and defense and offense. A seventh category is added, negative selfpresentation, to capture the entirety of the perpetrator's descriptions in news coverage. 
Recall van Dijk's (2015) six discursive strategies: positive self-presentation, denial and counter-attack, moral blackmail, subtle denials, mitigation, and defense and offense. I added a seventh discursive strategy: negative self-presentation. I included negative self-presentation to ensure I captured all of the perpetrator's descriptions in news coverage, rather than limiting myself to instances of positive descriptions of the perpetrator. Negative self-presentation will be described in greater detail below. I examined the entire news article, as well as the headline

My method for determining discursive frames follows Gamson and Modigliani's (1989) approach. Gamson and Modigliani examined news coverage of an oil spill, and argued that media frames consist of "metaphors, exemplars (i.e., historical examples from which lessons are drawn), catchphrases, depictions, and visual images (e.g., icons)" (p. 3). I used similar logic, and looked for words and phrases that seemed to capture van Dijk's (2015) six discursive strategies. My unit of analysis is manifest words and phrases that constitute 'frames.' Specifically, I found words or phrases in news coverage that revealed van Dijk's six discursive strategies, coded each word or phrase as a distinct frame, and counted each frame as an expression of one of van Dijk's six discursive strategies. I did not account for the number of frames in each news article because I was interested in the total number of frames used in news coverage of the Chapel Hill shooting, as well as the differences in the use of frames between regional and national news coverage. By manifest, I mean that the words or phrases are clear or obvious in their meaning. By frame, I mean a word or phrase that, in context, captures a discursive strategy. For instance, a manifest word to demonstrate an individual's positive self- 
presentation would be a description of him or her as "kind," because this word clearly reflects a positive and favorable light. On the other hand, a phrase like "interesting character," would not be coded, as the description is vague, and could be interpreted as positive or negative.

Before coding each frame, I re-read the news story to ensure that my comprehension of the text reflected manifest content. If I was unsure if the text reflected manifest content, then I did not code the instance as a frame. On the other hand, if I felt confident that the text reflected manifest content, I coded each instance of a frame, and counted each occurrence as one instance. Note that one news article might contain multiple frames in one discursive category, and it might also include more than one type of discursive frame category. For instance, there can be three words of phrases coded as denial and counter-attack, and two words or phrases coded as subtle denial frames, all of which occur in the same news article. Further, words or phrases coded as one of van Dijk's six discursive strategies could overlap with other frames. For instance, the word 'incident' in the sentence 'this was an 'isolated incident' could be coded under the mitigation frame, as well as the subtle denial frame. This is because the word 'incident' is used as a euphemism to describe the crime, thus satisfying the conditions for a mitigation frame. The word 'incident' is also used in the phrase 'isolated incident,' which is a phrase presented in quotation marks, making the phrase 'isolated incident' a subtle denial frame. I also looked for whether the word or phrase was a quote from a source or not, and to what or whom the word or phrase was attributed. I examined the context of the words and phrases used in news stories to ensure they were descriptive of the Chapel Hill shooting 
exclusively. Next, I used critical discourse analysis to guide my interpretations of the frames.

Consider the following news article as an example of my coding process. The news story is from the Australian news source, The Daily Telegraph, and centers on George Zimmerman, a 28-year-old man of Caucasian and Hispanic descent, who fatally shot Trayvon Martin, a 17-year-old African American teenager.

'Racist' vigilante tried for murder

THE murder trial has started of a volunteer neighbourhood watchman who shot dead an unarmed black teenager, inflaming racial tensions across the US.

George Zimmerman, 29, has pleaded not guilty, saying he shot Trayvon Martin, 17, in self defence on the rainy night of February 26, 2012, after the teen knocked him to the ground and started bashing his head against the footpath.

Mr. Martin's supporters accuse Zimmerman of racial profiling, saying he ignored police advice and pursued Mr. Martin, who was unarmed and had no criminal record.

The case ignited widespread protests after police initially declined to charge Zimmerman, and sparked debate over Florida's "Stand Your Ground" gun law, which allows firing in self-defence even when fleeing is an option.

Prosecutor John Guy sent a jolt through the courtroom with his opening statement yesterday, using words he said were uttered by Zimmerman in a call to a police dispatcher as he followed Martin through the gated community.

"F...ing punks," he said, quoting Zimmerman, telling jurors the offensive language revealed the accused's attitude toward the teen.

"When Zimmerman saw Trayvon, he didn't see a young man walking home. Instead, he profiled, pursued and killed Trayvon," he said.

Defence lawyer Don West said the shooting, while tragic, was not murder: "The evidence will show that there are no monsters here. It is a sad story. George Zimmerman is not guilty of murder... he shot Trayvon Martin in self-defence after being viciously attacked."

Sean Noffke, the dispatcher who spoke to Zimmerman, recalled that when Zimmerman told him he was following someone he replied: "We don't need you to do that." 
Lead defence lawyer Mark O'Mara insisted there was no racial motive. Zimmerman is the son of an American father and a Peruvian mother.

Zimmerman was on patrol in the Sanford community, which had seen a string of recent robberies, when he spotted Martin walking in a hooded sweatshirt, called 911 and pursued him.

Martin, who was returning from a shop after buying Skittles and an iced tea, was shot dead.

(“"Racist' vigilante tried for murder," 2013, p. 24)

I first followed Culler's (2011) method of an initial deep reading to get a sense of the news story. This step allowed for acquiring knowledge through reading the narrative, thus gaining knowledge through 'sense-making.' I then re-read the article and searched for manifest content (i.e., words or phrases) that described the perpetrator, the shooting, and the shooting's motivation. Next, I looked for words and phrases in the descriptions of the perpetrator, the shooting, and the shooting's motivation, and then placed the word or phrase into the coding scheme according to their respective categories (see Figure 3.1). I noted the context of how the words or phrases were used to ensure my reading of the descriptions revealed the discursive strategies, and ensured that the words and phrases were descriptive of the Trayvon Martin shooting exclusively. In the example above, I marked each word or phrase that demonstrated the six discursive strategies: the word "racist," and the phrases "shot Trayvon Martin in self-defence," and "he shot Trayvon Martin, 17, in self defence." I counted each word and phrase as separate instance of denial of racism, and deduced that there were a total of three instances of denial of racism in the news article. I coded the word "racist" as a subtle denial frame, since the word "racist" was presented in quotation marks, therefore suggesting that the word "racist" is an "unfounded accusation" (van Dijk, 1992, p. 185). I counted the two phrases "shot 
Trayvon Martin in self-defence," and "he shot Trayvon Martin, 17, in self defence" as two separate instances of denial and counter-attack. The phrases were coded as instances of denial and counter-attack because the phrases provide a motivation for the shooting that is not racism, i.e., "self-defence" (van Dijk, 2015).

Next, I discuss the discursive strategies used in the coding scheme. The coding scheme will be used to examine whether these discursive strategies occurred or were absent in news coverage, and how they were characterized in news coverage.

\section{Operationalization}

Positive self-presentation. I looked at how individuals in news stories were characterized 'positively.' By positive self-presentation, I mean if an article discussing the murders describes the perpetrator with words or phrases that highlight his qualities in a positive light. Positive self-presentation can include descriptions of being an advocate for marginalized social groups, or discussing a career-choice to convey a respectful position in society. Note that positive self-presentation can only refer to an individual from the dominant racial group (i.e., White), since van Dijk (2015) refers to the dominant racial group when using the term 'self' in 'positive self-presentation.' I counted each frame that used a word or phrase in the positive self-presentation discursive strategy (please see figure 3.1). I then went back and examined the frames used in the sentence in order to see the context of how the words were used, and determine whether the word I coded as positive self-presentation was used in the context of a positive description of the perpetrator. In news coverage of the Chapel Hill shooting, if an article described the perpetrator in favorable terms, such as 'champion,' or 'advocate,' I will mark the instance 
as positive self-presentation after verifying the context of the word's use in sentences describing the perpetrator. If I encountered a word that I was not certain whether it could be interpreted as positive self-presentation or not, I did not include it. I counted the words and/or phrases in each instance of self-presentation as one frame. A news story could have more than one frame of self-presentation.

To guide my coding decisions, I used the following scenario. Consider a news story discussing Trayvon Martin, a 17-year-old African American teenager who was fatally shot by George Zimmerman, a 28-year-old man of Caucasian and Hispanic descent. Consider the following example of an article using the positive self-presentation strategy:

But Zimmerman's family, his neighbors and his lawyer paint a different picture:

That of a devoted neighbor, keen enough to protect the neighborhood that residents, in establishing a local Neighborhood Watch group last year, appointed him the captain. (Jonsson, 2012, para. 9).

This example consists of multiple separate units; the phrases "devoted neighbor," "protect the neighborhood," and the word "captain," are three separate instances of positive self-presentation. I expanded my search to single units of words or phrases (i.e., frames) that occurred within news stories based on the context of how the words or phrases were used. The context of the word or phrase is taken into account, because in some cases, one word might not be enough to reveal the meaning being expressed. For example, the word "protect," does not reveal the context of the word as much as "protect the neighborhood." The example above shows how positive self-presentation since it 
paints Zimmerman through favorable terms in context (e.g., "devoted neighbor," "protect the neighborhood").

Negative self-presentation. I recognized I would also need to code for negative self-presentation, which is not discussed by van Dijk. Therefore, if an article included negative self-presentation, I noted it as well. By negative self-presentation, I mean if an article describes the perpetrator in a way that highlights his qualities in a negative light, or through unfavorable terms (e.g., 'racist,' 'bully,' 'threatening'). To guide my coding decision, I used the following scenario. Consider the excerpt from Washington Post about George Zimmerman, the man who fatally shot a 17-year-old African American teenager, using negative self-presentation,

Aside from the simple fact that despite his acquittal, some Americans consider him to be a cold-blooded murderer, he was raised Catholic, eschewing the limelight (Andrews, 2016, para. 7).

This is an example of negative self-presentation since it paints Zimmerman through unfavorable terms in context (e.g., "cold-blooded murderer"). This is also a clear, manifest phrase that frames the perpetrator in a negative way, since "cold-blooded" and "murderer" are both blatantly negative terms used to describe an individual.

I therefore looked for adjectives or descriptors that framed the perpetrator in unfavorable terms. Referring back to the example of George Zimmerman, I looked for adjectives in the sentence that can be interpreted as an obvious and blatant negative attribute. 
Denial and counter-attack. By denial and counter-attack, I mean when the press denies racism by portraying a racist act motivated by a rationale other than racism (van Dijk, 2015). For example, the press can deny racism by framing an assault against a minority person as an act of self-defense, rather than pointing to the rationale of racism. Van Dijk argues that when the news denies racism using this strategy, it reverses the roles of who are the racists, claiming that those who perceive the incident as racist are the ones who are, in fact, racist. Denial and counter-attack go hand-in-hand because news articles that engage in this strategy deny racism by presenting it as the truth, while at the same time framing opponents of the truth as racist. I will therefore find words or phrases used to describe the shooting as being motivated by a rationale other than racism or discrimination (please see Figure 3.1).

To guide my coding decisions, I used the following scenario. Recall the excerpt of the shooting of Trayvon Martin used in the positive self-presentation example. The following comment is an example of 'denial,' and refers to the police chief's comment on why the shooter, George Zimmerman, was not arrested for killing Trayvon Martin:

Even the police chief recognizes this reality, even while disputing claims of racial bias in the investigation: "Our investigation is color blind and based on the facts and circumstances, not color.” (Blow, 2012, p. A021).

By using the words "color blind" and "not color," the police chief denies racism. Van Dijk (2015) would consider this example as denial and counter-attack because he considers denial and counter-attack as one and the same. By stating that the police chief is "color blind," the news article states that the entire affair is separate and distinct from 
racism. Note that I would count this as a single frame, because "color blind" and "not color" refer to the same instance of denial and counter-attack.

To code for denial and counter-attack, I will first read news articles and look for words that frame the crime with a manifest denial of racism. More specifically, I will look for adjectives or descriptors that frame the crime as motivated by a reason outside of racism, discrimination, or hate. Referring back to the police chief's quote on describing his investigation on Zimmerman as an example, I will look for words that present a rationale besides racism, which will be interpreted as denial and counter-attack. Thus, the frame will identify the crime's motivation as something other than racism.

Moral Blackmail. By moral blackmail, van Dijk (2015) asserts that the press frame anti-racists as preventing the press from being able to report facts in fear of being labeled racist. Consequently, journalists argue they must have the right to engage in acts that can be seen as taboo, such as using labels that may be interpreted as racist, in order for them to fully cover a news story. Van Dijk argues that the press show that they feel morally blackmailed into not doing their job of wholly covering a news story by being censored by anti-racists, since in order for them to fully cover a news story, they must be able to say things that would otherwise be considered negative or perceived as racist. I will count the words or phrases used in news articles that frame the press as unable to do their job of covering the story in fear of being labeled racist, and code the words or phrases as moral blackmail (see Figure 3.1).

To guide my coding decision, I used the following scenario. Consider the following quote from television host Bill Maher, who is notorious for saying 
inflammatory remarks on political issues. The quote is an excerpt from a discussion he was having about Arabs and Muslims two weeks after the September 11, 2001, attack on the World Trading Center in New York. The following quote refers to Bill Maher's response after being accused of insulting Arabs and Muslims in his description of the Muslim community:

"I am not insulting Arabs and Muslims. I am keeping it real like I do with everybody else, (Jalabi, 2014, para. 19).”

Turn your attention to the phrase "I'm keeping it real." In this example, Maher denies racism by framing his "insulting” remarks towards Arabs and Muslims as factual descriptions, i.e., "keeping it real," rather than being racist. Moral blackmail denies racism by framing racist descriptions as factual (i.e., "real").

In coding the articles for moral blackmail, I will look for words that frame individuals as unable to use descriptions that could appear to be racist. Referring back to the example of Bill Maher, I would look for words or phrases in the sentence that, in context, can be interpreted as moral blackmail, such as "I'm keeping it real." Note that I am only looking for manifest frames. In other words, I am only selecting words or phrases clearly used as moral blackmail. If I encounter a word that I is uncertain will not code it. I will then go back and examine the sentence as a whole in order to see the context of how the words and phrases are used, and determine whether the frame is moral blackmail.

Subtle denials. By subtle denials, I mean an instance that casts doubt on accusations of racism. Van Dijk argues that the use of quotation marks in print may 
suggest doubt about the validity of accusations of racism. Using quotation marks is not simply a journalistic tool used when reporting opinions. Van Dijk (1992) argues that quotation marks imply "unfounded accusation" (p. 185) In addition, subtle denials instantiate instances of racism with doubt. To guide my coding decision, I used the following scenario. For example, consider an article discussing the issue of sexual assault in college campuses:

The Washington Post's headline was grim: "Hundreds of colleges had zero rape reports and that could be worrisome." That was in 2014, when hysteria over 'the rape culture' in US colleges was starting to take hold. Madness ensued. (Arndt, 2016, p. 24).

By putting "the rape culture" in quotation marks, the article implies that rape culture is questionable and possibly unfounded (van Dijk, 2015).

In coding the articles for the Chapel Hill shooting, I will first read news articles and look for words that subtly deny accusations of racism. More specifically, I will look for words that are used to incite doubt in the reader, such as having accusations of racism presented within quotation marks. I will count the words or phrases used to put accusations of racism in quotation marks as a subtle denial frame (see Figure 3.1). Note that I am only looking for manifest frames. In other words, I am only selecting words clearly used as a subtle denial. If I encounter a word that raises uncertainty, I will not code it. I will then go back and examine the sentence as a whole in order to examine the context of how the frame is used. 
Mitigation. By mitigation, I mean how actions are minimized and downplayed through the use of euphemisms, or re-attributed to other individuals or intangible entities. I counted frames that used words or phrases characterized as the mitigation strategy (see Figure 3.1).

To guide my coding decision, I used the following scenario. Consider an article discussing Christopher Harper-Mercer, a 26-year-old White man who carried out a mass shooting at Umpqua Community College in Oregon in 2015, killing nine people. An article using the mitigation strategy reported the shooting by using euphemisms for murder. For instance:

“Christopher Harper-Mercer took nine lives ("No Mercy,” 2015, para. 9).” This is mitigation because the newspaper frames the crime in a way that downplays Harper-Mercer's actions (e.g. avoiding words associated with "murder" or "shooting"), thus lessening the weight of the crime. Furthermore, downplaying the actions of the perpetrator removes the gravity of his actions. Another example of mitigation would be a quote from Harper-Mercer's mother:

"My son has mental issues. (Healy \& Lovett, 2015, p. A1)."

This sentence mitigates Harper-Mercer's crime by redistributing blame. Rather than blaming Harper-Mercer for his crime, mental illness is blamed.

In coding the articles for the Chapel Hill shooting, I will first read news articles and look for words that minimize the crime. More specifically, I will look for words used as euphemisms such as "event," instead of "crime," or "murders." Referring back to the quote about Harper-Mercer killing nine people, I would look for words in the sentence 
that were used to minimize the crime. Further, I will look for frames that attribute the crime to another entity, such as mental health as the rationale for the crime. Note that I am only looking for manifest frames. In other words, I am only selecting words clearly used as minimizing the crime, such as euphemisms or reattributing blame. If I encounter a word that creates uncertainty, I will not code it. Next, I will go back and examine the sentence as a whole in order to examine the context of how the frame was used, and determine whether the frame minimizes the crime through euphemisms or reattribution of blame to another entity.

Defense and offense. Defense and offense stray from more subtle approaches of denial to directly address opposition. Simply put, using defense and offense is a strategy that directly addresses individuals who oppose beliefs or statements made in the press. I will note words or phrases used to directly address anti-racists (see Figure 3.1).

To guide my coding decision, I will use the following scenario. Recall the case of the shooting of Trayvon Martin. An article following the defense and offense strategy reports the story as follows,

"I'm tired of hearing about this race thing," Hall said. "It could be an element in it ... but I never would have thought of him as being a racist. His father was in the Army and was a white American and his mother was Peruvian. That makes him 50 percent Peruvian. A lot of stuff I hear, it irks me because people are drawing their own conclusions with very little evidence." (Pearce, 2012, para. 19). This excerpt explicitly denies racism in several ways: Hall says "I never would have thought of [Zimmerman] as racist" and "people are drawing their own conclusions with 
very little evidence.” The quote directly addresses the anti-racists, describing them as people quick to judge someone with little evidence to support their accusations. The phrase "drawing their own conclusions with very little evidence" portrays the anti-racists as ill informed, therefore framing their accusations of racism as illegitimate. Thus, racism is denied by framing the accusation of racism as baseless.

Before coding, I will first read news articles and look for words and phrases that directly address defense and offense. More specifically, I will look for words used to frame anti-racists as paranoid, liars, or other words that question the legitimacy of the anti-racists and their accusations. Words and phrases that frame anti-racists as illegitimate extend to framing the accusations of racism as illegitimate. Referring back to the example of Zimmerman, I will look for words in the sentence that are used to directly address and oppose anti-racists. Note that I am only looking for manifest frames. In other words, I am only selecting words clearly used to frame anti-racists in an "offense and defense" manner (van Dijk, 2015). If I encounter a word that raises uncertainty, I will not code it. I will then go back and examine the sentence as a whole in order to examine the context of how the frame was used.

Having all of this in hand, I will analyze how the six discursive strategies describe the Chapel Hill shooting, and how racism is 'denied.'

\section{Comparison of National and Regional News}

Having drawn news sources from national and regional news coverage, I wanted to see if there were differences in the way national and regional news coverage denied racism. 
RQ 2: In what ways does news coverage of the Chapel Hill murders compare across national and regional stories in terms of van Dijk's six discursive strategies?

The comparison will emerge from my initial deep reading and coding for my first research question (In what ways does the news coverage of the Chapel Hill murders 'deny racism' through the use of van Dijk's six discursive strategies?). After obtaining the frames for each discursive strategy, I will organize them according to whether the frame was found in a national or regional news source, and then compare how the frames were distributed across national and regional news stories, and discuss patterns I find in the results section.

\section{Time Frame}

News articles were collected through the LexisNexis database. News articles were selected from the time frame of February 11, 2015, to March 11, 2015, due to the fact that a significant number of articles relating to the Chapel Hill shooting fell within that time frame (see Figure 3.2).

\section{Figure 3.2. Number of news articles on the Chapel Hill shooting in one month}

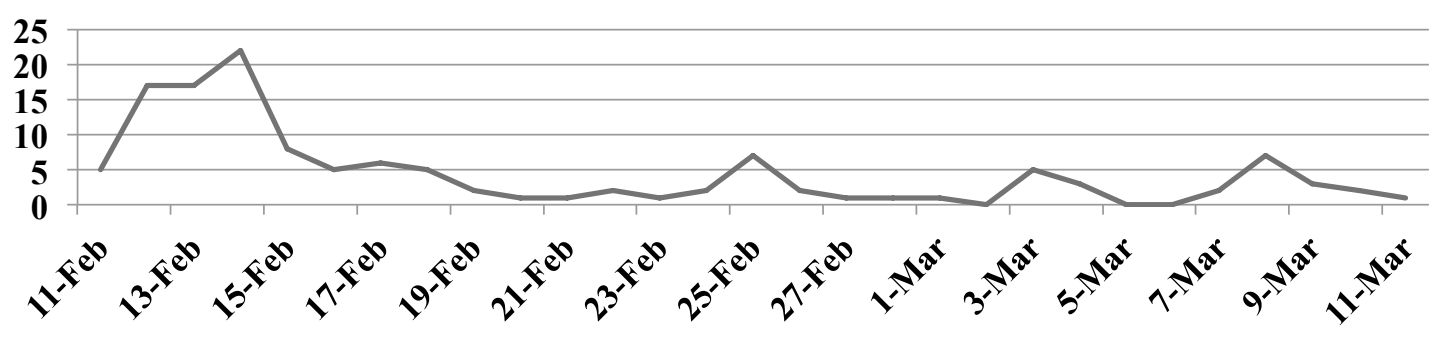

Key: Number of Articles

Figure 3.2. A chart illustrating the mnumberof news articles on the Chapel Hill shooting over 30 days. 
A preliminary search for the words 'Chapel Hill' and 'shooting' yielded 129 articles from the database: 85 of the articles (65.8\%) were concentrated in the first week of the selected time frame (February 11, 2015 to February 18, 2015). The amount of coverage decreased after the first week, with 16 articles (12.4\%) falling within the second week (February 19, 2015 to February 25, 2015), dropping to 12 articles (9.3\%) during the third week (February 26, 2015 to March 4, 2015), and 15 articles (11.6\%) in the fourth week (March 5, 2015 to March 11, 2015).

Among the 129 articles found, 56 were discarded because the word-search term 'shooting' generated articles about basketball teams from North Carolina.

\section{Article Selection}

Now left with 73 articles, recall that I wanted to compare mainstream news with regional news. From the 73 remaining articles, 37 more articles were discarded because they did not meet the requirement of major mainstream news channels or regional news channels. For example, a news source such as The El Paso Times was discarded because it is not a national or North Carolinian source. This left the number of news articles at 29. 
The most prominent mainstream news channels included the New York Times,

Washington Post, and USA Today, while regional news channels included The Herald-

Sun and Star-News (see Figure 3.3).

\section{Figure 3.3. Number of articles from each news source within natural and regional news coverage.}

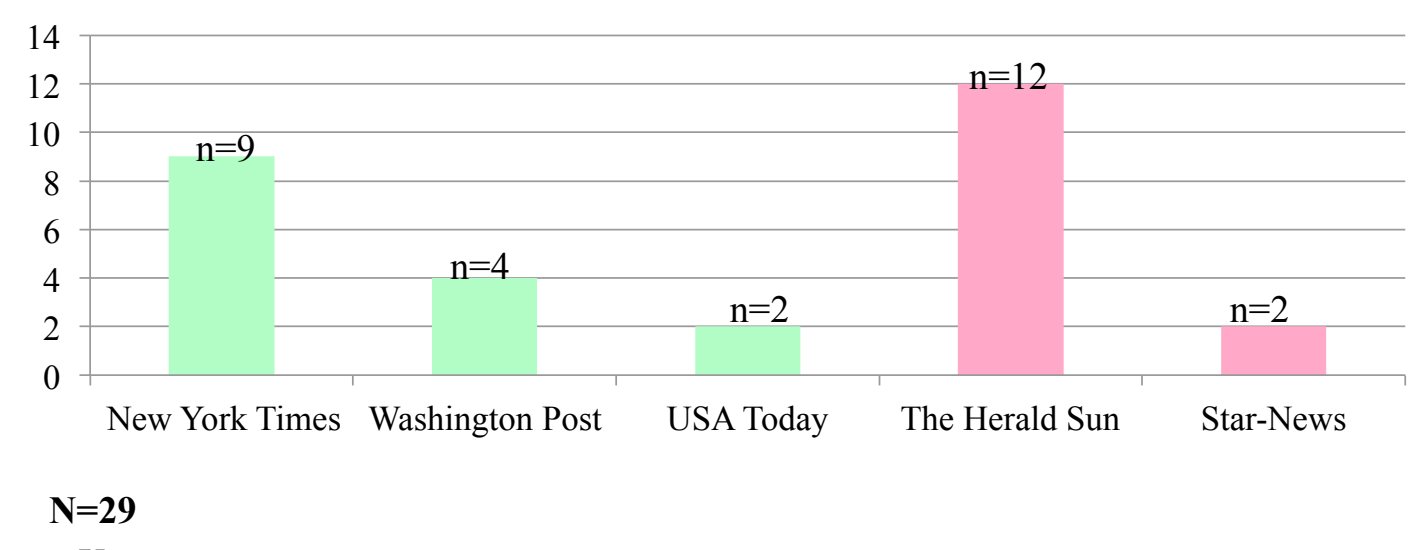

Key:

Number of Regional Articles

Number of National Articles

Figure 3.3. A chart illustrating the number of news articles fromo each news source. The news sources are organized by whether they come from national or

The final pool consisted of 29 articles: 15 from the selected mainstream news channels:

the New York Times (9), the Washington Post (4), and USA Today (2), and 14 from regional news channels: The Herald-Sun (12), and Star-News (2). 


\section{Chapter 4: Results}

Recall the first research question: In what ways does the news coverage of the Chapel Hill murders 'deny racism' through the use of van Dijk's six discursive strategies? I first performed a deep reading of the 29 news articles. I read about the descriptions of the shooting, the reasons behind the shooting's occurrence, and the individuals involved in the shooting.

I marked words and/or phrases that reflected a frame that characterized a discursive strategy: positive self-presentation, negative self-presentation, denial and counterattack, moral blackmail, subtle denials, mitigation, and defense and offense, which I detail below. After re-reading each frame for its context, I placed all frames into their respective categories ${ }^{1}$. I discuss below each occurrence of the discursive strategies in the order of most occurring to the least.

\section{Figure 4.1. Totality of Discursive Frames}

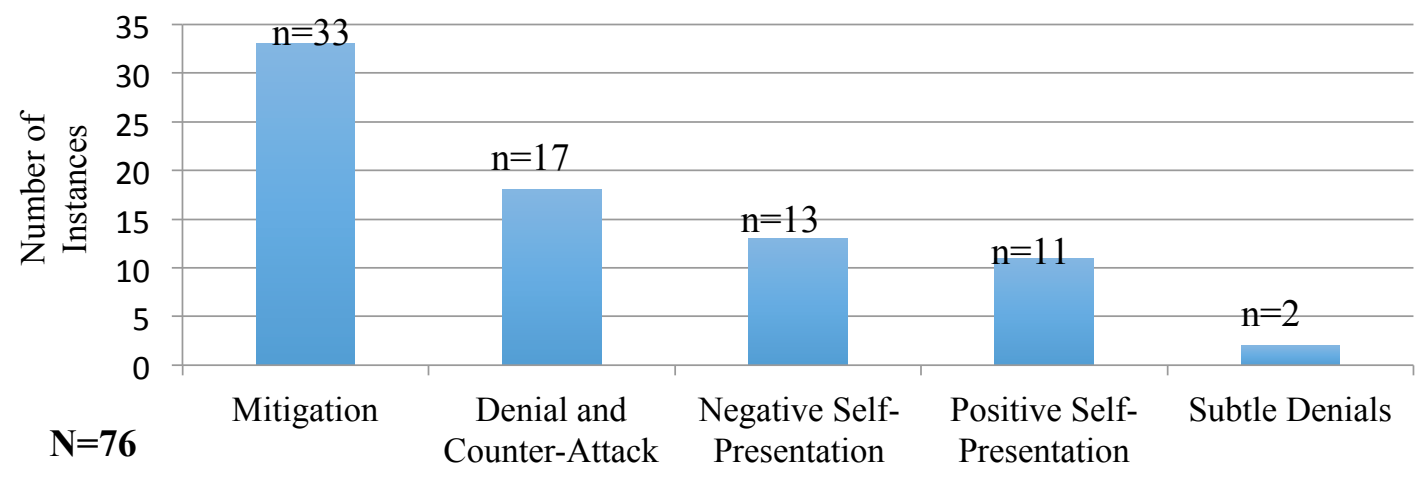

Key:

Number of Instances of Each Frame Types of Dicursive Frames

Figure 4.1. A chart illustrating the number of times each discursive frame was found in news coverage of the Chapel Hill shooting.

\footnotetext{
${ }^{1}$ Note that I collapsed words or phrases that were the same, or slightly differed, into a single subcategory. For instance, the word "champion," "champions," and "championed" were collapsed into one subcategory of the word "champion."
} 
There were a total of 76 instances of discursive frames found in news coverage of the Chapel Hill shooting: 33 instances of mitigation (43\%), 17 instances of denial and counter-attack (22\%), 13 instances of negative self-presentation (17\%), 11 instances of positive self-presentation (14\%), and two instances of subtle denials (3\%). No frames were found for moral blackmail and defense and offense. While the average number of frames found in each article was consistent $(M=2.6)$, there was one article from regional news coverage that accounted for most of the mitigation frames (11 instances), and one article from national news coverage that accounted for most of the negative selfpresentation frames ( 8 instances) (see Appendix B). There were ten articles that had zero instances of discursive frames. In the next section, I discuss findings in each discursive strategy in detail.

\section{Data Analysis}

\section{Mitigation}

Mitigation was the most frequently occurring strategy, and was used 33 times in news stories, which represented $43 \%$ of all frames. Mitigation described the shooting by using euphemisms, and by reattributing the crime to another entity other than the shooter. 


\section{Figure 4.2. Number of instances of words or phrases coded as 'mitigation.'}

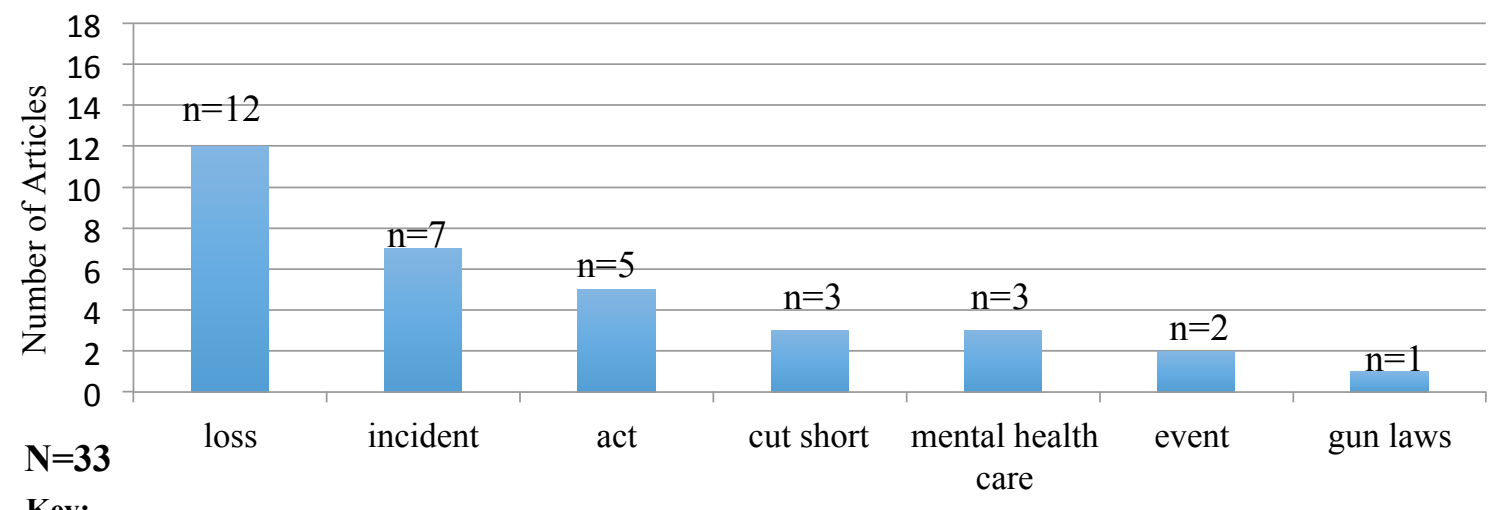

Key:

Mitigation

Words and Phrases

Figure 4.2. A chart illustrating the number of times each word or phrase was found and coded as 'mitigation.'

I found that the frames fell into two subcategories of mitigation: reattribution and euphemisms. In other words, frames that were characterized as mitigation either reattributed the crime to another entity (i.e., mental health), or used softer euphemisms to describe the crime. I will first present my findings for frames in the reattribution subcategory, and then present my findings for frames found in the euphemisms subcategory.

\section{Reattribution}

The crime was mitigated was by attributing the crime to another entity: mental health. This statement was used a total of three times in news coverage. Consider the following quote from The Herald-Sun:

Karen Hicks' attorney, Robert Maitland, said Tuesday's shootings highlight the importance of access to mental health care and services, as well as removing the stigma of asking for such services. 
This is a representative quote that depicts how the use of the phrase "mental health care" was used in news coverage of the Chapel Hill shooting. By reattributing the crime to mental health, news articles mitigate the crime because it can suggest that the perpetrator was not entirely responsible for his actions due to mental health issues. This can shift attention and blame away from the perpetrator and onto the issue of mental health care, and can even frame the perpetrator as a victim of poor social and institutional structures that create a stigma around receiving mental health care. Another instance of reattributing the crime to another entity was the focus on gun laws rather than racial discrimination. For instance, consider the following quote from USA Today:

Focus on gun laws. It's sad but maybe easier to put stricter gun laws in than eliminate a lifetime of hate ("Killing of three Muslims spurs fear of religious bias," 2015, p. 6A).

The use of the phrase "gun laws" was only used once in news coverage. Like mental health, the focus on gun laws shifts blame away from the perpetrator's actions.

I will now move on to illustrating how the second subcategory of mitigation, euphemisms, denied racism in news coverage of the Chapel Hill shooting.

\section{Euphemisms}

One way news articles labeled the outcome of the shooting was using the phrase "loss of life" as a euphemism for the victims' murders. This occurred a total of twelve times in news coverage. Consider the following excerpt from The Herald-Sun:

A statement from the Barakat family released Wednesday afternoon expressed great grief for the loss of life ("Three young lives," 2015, p. A1). 
I chose to code the phrase "loss of life" as a mitigation frame because the phrase frames the murders as a loss, rather than describing the murders with terms that revealed their weight and magnitude. I recognized this frame occurring by performing a deep reading of the articles and marking terms that used softer euphemisms to describe the shooting, rather than using harsh, loaded terms. Using a softer word or phrase as a euphemism to describe the shootings can minimize the crime, therefore mitigating it (van Dijk, 2015).

A prominent euphemism used to describe the crime was the word "incident." The euphemism was used seven times in news coverage of the Chapel Hill shooting. For instance, consider the following quote from The New York Times:

"I can say with absolute belief that this incident had nothing to do with religion or the victims' faith, but it was related to a longstanding parking dispute that my husband had with the neighbors," she said (Katz \& Perez-Peoa, 2015, p. A01). I chose to frame the word "incident" as mitigation because of the way the description reduces the crime as an incident that occurred, rather than a shooting.

The word "incident" was also used to describe the crime as isolated. For example, examine the following quote from USA Today:

U.S. Attorney for the Middle District of North Carolina Ripley Rand, said the shootings were apparently an “isolated incident” (Stanglin \& Winter, 2015, p. 3A).

I chose to code the word "incident" as a mitigation frame because it described the crime as an incident, which reduces the crime and its details to a mere incident. Further, the word "incident" was described as "isolated," which describes the crime as removed and 
random from society, therefore distancing the crime and framing it as unusual or irregular. By framing the crime as "isolated," it distances the crime from motives such as racism, as well as distances the perpetrator from the community, thus framing the perpetrator as a member of the out-group. Describing the attack as an "isolated incident" frames the shooting as a random occurrence, and one that is not consistent with the regular actions and beliefs of society towards minority groups. In other words, the shooting is described as an unusual incident that is uncommon and unlikely to occur again. This denies racism by framing the shooting as a mere "incident," thus mitigating the shooting and the subsequent murders, and frames the shooting as "isolated," therefore, random, and thus frames crimes similar to the Chapel Hill shooting as unlikely to occur again.

Another euphemism that was used to describe the crime was the word "act." This euphemism was used a total of five times in coverage. Consider the following quote from The Washington Post:

"Our investigators are exploring what could have motivated Mr. Hicks to commit such a senseless and tragic act," Chris Blue, the Chapel Hill police chief, said in a statement (Sullivan \& Berman, 2015, p. A01).

The phrase "senseless and tragic act" is used to describe the shooting and murders, thus reducing the crime and its consequences to an "act." I chose to code phrase "tragic act" as mitigation because of the manifest way it described the crime in a more subdued manner. Using the phrase "tragic act" to describe the crime omits details of the crime, as well as 
avoiding the use of harsher terms to describe the shooting itself, therefore minimizing and diminishing the weight of the crime. Thus, the crime is mitigated.

Another instance of euphemisms used to describe the crime was the word "event." This occurred two times in news coverage of the Chapel Hill shooting. For instance, consider the following excerpt from The Herald-Sun,

The events that led to the deaths of 23-year-old Deah Shaddy Barakat, 21-yearold Yusor Abu-Salha and 19-year-old Razan Mohammad Abu-Salha were still hazy more than 24 hours after the first 911 call came in ("Three young lives," 2015, p. A1).

I chose to code the word "event" as mitigation because of the manifest way it described the crime with a less charged or descriptive term, rather than words like "murders," or "shooting." Using such euphemisms for the crime articles can mitigate the weight of the shootings. Attention is drawn away from the fact that three people were murdered, shootings, or violence involved in the crime committed, and the crime is reduced to an "event." In this way, the news article minimizes the crime, and is made to appear less severe. Thus, the crime is mitigated.

Another way the crime was mitigated was by describing the shooting and murders with the phrase "cut short," which was used a total of three times in news coverage of the Chapel Hill shooting. For instance, consider the following quote from The Herald-Sun: Three young lives were cut short Tuesday evening, all over what police believe was a dispute over a parking spot in a quiet community in Chapel Hill ("Three young lives," 2015, p. A1). 
I chose to code the phrase "cut short" as a mitigation frame due to the way it described the murders with a more gentle euphemism. By using a softer phrase to describe the shooting, such as describing the murders as lives that were "cut short," the crime is minimized (van Dijk, 2015). Using the phrase "cut short," to is a less inflammatory phrase to use to describe the act of murdering three individuals, rather than using more charged terms, like "murder" or "killed."

\section{Denial And Counter-Attack}

When describing the motive of the shooting, news articles used the discursive strategy of denial and counter-attack in $22 \%$ of all discursive frames. Recall that denial and counterattack is when the press attack individuals who have a different view than the press, while simultaneously defending individuals who agree with the press's view in news articles (van Dijk, 2015). Recall that this discursive strategy operates by framing denials of racism as truth in the press.

\section{Figure 4.3. Number of instances of words or phrases coded as 'denial and} counter-attack.'

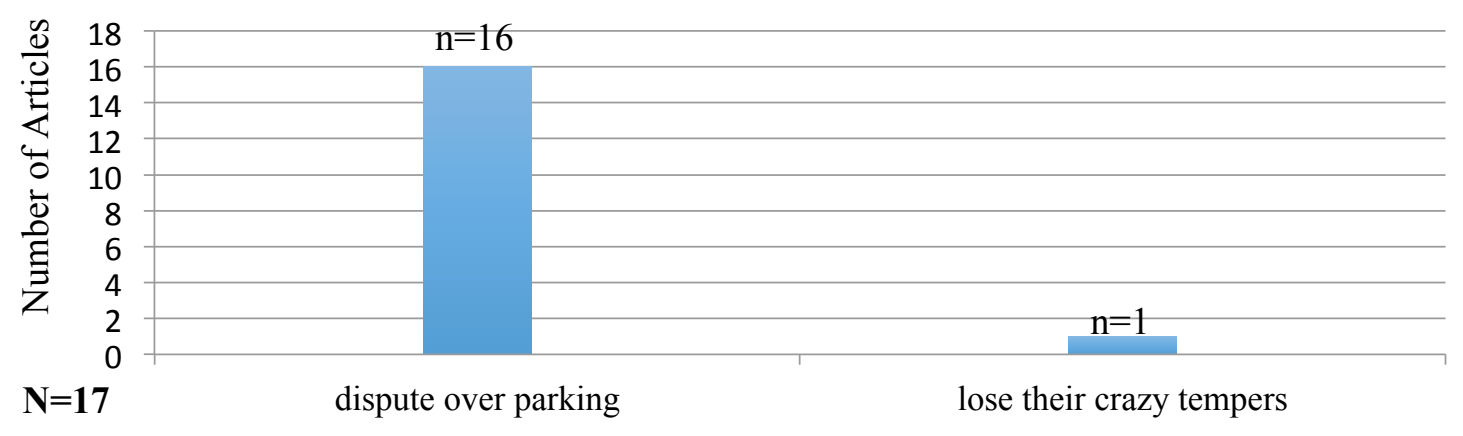

Key: $\quad$ Words and Phrases

Figure 4.3. A chart illustrating the number of times each word or phrase was found and coded as 'denial and counter-attack.' 
News articles describe the crime as being the result of a parking dispute 16 times. The two excerpts below are representative of assertions across news articles that the attacks were inspired by a parking dispute. Consider the following quote from The Herald-Sun:

"Law enforcement officials have said the shootings stem from a long-standing parking dispute in the Finely Forest neighborhood," (Horsch, 2015, p. A8). I chose to code the word "parking dispute" as a denial and counter-attack frame because it was a manifest term that presented the motivation behind the crime as something other than racism or discrimination.

Another example where the shooting was presented as motivated by a parking dispute is seen in The Herald-Sun:

Officials said the preliminary motive for the killings was an ongoing neighborhood problem with parking, but family members of the victims have been calling for their deaths to be investigated as a hate crime ("Details into the investigation," 2015, p. A1).

I chose to code the phrase "problem with parking" as denial and counter-attack because of the manifest way that the news article attributes the crime's motivation as a problem with parking, rather than pointing to motivations like racism or discrimination.

Another example of news coverage framing the shooting as being motivated by a parking dispute was by using the phrase "parking issues." Examine the following quote from The Herald-Sun: 
"Well obviously, it's not, I would say normal, or within the normal range of behavior for someone to shoot three people over parking issues," Maitland said (“Many mysteries," 2015, p. A1).

I chose to code the phrase "parking issues" as a denial and counter-attack frame because of the blatant and obvious way that the news article describes the shooting's motivation as a result of parking issues rather than racism or discrimination.

Another way one news article describes the shooting's motivation as the result of the perpetrator losing his temper. This occurred once in USA Today:

I don't really think we should assume it's a hate crime just because the victims were Muslim. People lose their crazy tempers all the time ("Killing of three Muslims spurs fear of religious bias," 2015, p. 61).

I chose to code the phrase "lose their crazy tempers" as denial and counter-attack because of the way the motivation of the crime was pointed to a reason outside of racism or discrimination. By framing the reason of the crime as a loss of temper, the attention of the crime's motivation is shifted away from the racism, and onto issues like managing one's temper. Thus, by presenting a statement outside of racism and discrimination, the news article denies racism.

Negative Self-Presentation

Negative self-presentation was also used to describe the perpetrator. Although the perpetrator was portrayed in a negative light, articles steered away from framing Hicks as a racist, or someone motivated by discrimination against minority groups. Instead, articles focused on his character, framing the perpetrator as a threatening person who was 
seen as disruptive and aggressive. Negative self-presentation frames made up $17 \%$ of all discursive frames found in news coverage of the Chapel Hill shootings.

\section{Figure 4.4. Number of instances of words or phrases coded as 'negative self-presentation.'}

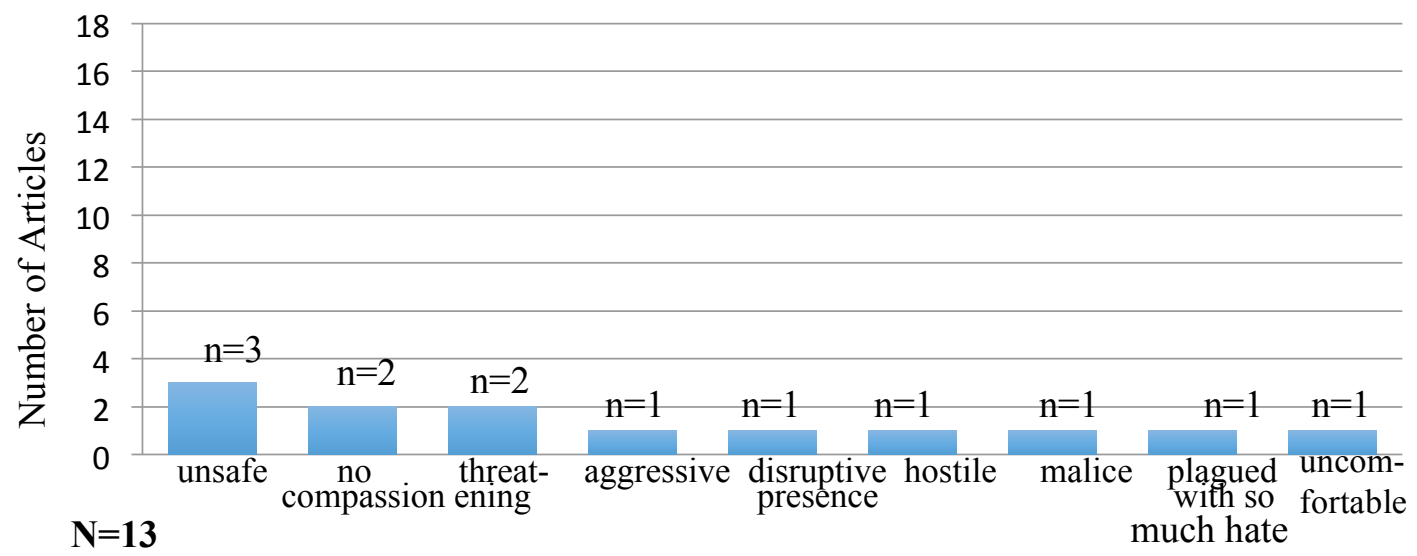

Key:

Words and Phrases

Negative Self-Presentation

Figure 4.4. A chart illustrating the number of times each word or phrase was found and coded as 'negative self-presentation.'

The most common word used to describe the perpetrator in a negative way was "unsafe." Consider the following quote from The New York Times:

A young female neighbor described Hicks as an angry man who made many of

the nearby residents on the 200 Summerwalk Circle feel unsafe (Katz \& Paulson, 2015, p. A014).

I chose the word "unsafe" as a word that represented negative self-presentation due to its negative description of the perpetrator. By framing the perpetrator as a person who made people close to him (i.e., his neighbors) feel unsafe, the article frames the perpetrator as an outsider to the community, as well as an outsider to the social in-group. 
Another word that was further used to describe the perpetrator negatively was "threatening," which was occurred two times in news coverage of the Chapel Hill shooting. For instance, consider the following headline from The New York Times, Accused of Murder, Remembered as Threatening (Katz \& Paulson, 2015, p. A014).

In the headline, the perpetrator is framed as a threatening individual. I chose the word "threatening" as an instance of negative self-presentation because it was a manifest, clear description that framed the perpetrator in a negative manner. By framing the perpetrator as a threatening individual, the news article frames the perpetrator as an individual that other members of the community did not feel safe to interact with, thus framing him as an outsider to the community. This is further exemplified in the second instance of the word "threatening" used to describe the perpetrator negatively. Note that both instances of labeling the perpetrator negatively occur in the same news article. Let us examine the second instance of the perpetrator being framed as threatening in the following excerpt from The New York Times:

None of them, of course, could have foreseen that he might be charged with murdering three people in a neighboring apartment on Tuesday: two sisters, Yusor Mohammad Abu-Salha and Razan Mohammad Abu-Salha, and Yusor's husband, Deah Shaddy Barakat -- all of them Muslim. But some neighbors felt threatened by his behavior (Katz \& Paulson, 2015, p. A014).

The use of the word "threatening" was used to describe the perpetrator as a person who made his neighbors feel threatened, and therefore, a person who was not seen as part of 
the social in-group. I chose to code this instance as negative self-presentation because of the blatant and manifest negative way in which the perpetrator was described.

The word "no compassion," was used to describe the perpetrator's character two times in news coverage. I chose to code the word "no compassion" as a negative selfpresentation frame because of the clear negative description that the word yields; being described as a person who has no compassion depicts the idea that the person does not care for others. Consider the following quote from The Herald-Sun:

Craig Hicks' ex-wife, Cynthia Hurley, said that before the couple divorced about 17 years ago, his favorite movie was "Falling Down," the 1993 Michael Douglas film about a divorced unemployed engineer who goes on a shooting rampage. "That always freaked me out," Hurley said. "He watched it incessantly. He thought it was hilarious. He had no compassion at all," she said. The context that the word "no compassion" was used in framed the perpetrator's character in a negative way. The perpetrator's first wife, Cynthia Hurley, uses an anecdote of the perpetrator's favorite movie to demonstrate his lack of compassion. This further frames the perpetrator as a deviant, who found a movie about a mass shooting humorous, and alarming his ex-wife. The quote therefore further removes the perpetrator from society.

The word "hostile" was used one time in news coverage to describe the perpetrator in a negative way. Consider the following example from The New York Times: 
He was the angry man on Summerwalk Circle, they said -- irritated about noise, irascible about parking, hostile to religion. And armed. (Katz \& Paulson, 2015, p. A014).

I chose to code the word "hostile" as negative self-presentation due to its blatant negative description of the perpetrator. The news article uses negative self-presentation to frame the perpetrator by describing the perpetrator as antagonistic towards religion, i.e., "hostile," thus framing him as an individual who was incompatible with people who had spiritual beliefs. This is the first instance of negative self-presentation that addressed the possibility of the crime being motivated by discrimination.

The term "aggressive" was used one time in news coverage to describe the perpetrator once in news coverage of the Chapel Hill shooting. Consider the following quote from The New York Times:

"He was definitely aggressive, and he spoke harshly when he was upset," she said (Katz \& Paulson, 2015, p. A014).

I chose to code the word "aggressive" as a negative term because it was a manifest negative description of the perpetrator.

The word "disruptive presence" was used to describe the perpetrator one time in news coverage. Let us examine the following excerpt from The New York Times:

Mr. Hicks was such a disruptive presence in the Finley Forest condominium complex that last year, residents held a meeting to talk about him (Katz \& Paulson, 2015, p. A014). 
I chose to code the word "disruptive presence" as a negative frame because it was an obvious, manifest negative description of the perpetrator.

Another word that was used to frame the perpetrator negatively was the word "malice," which was used one time in news coverage of the Chapel Hill shooting. Consider the following quote from The New York Times:

If those accounts do not prove what kind of malice was in Mr. Hicks's heart, the details that emerge indicate that whatever happened almost certainly was not a simple dispute over parking (Katz, 2015, p. A012).

I chose to code the word "malice" as a negative description because of the blatant, manifest negative way the word frames the perpetrator. The context of the word's use describes the perpetrator as someone who intended to harm someone. Thus, the perpetrator is framed in a negative manner.

Another word that framed the perpetrator negatively was the phrase "plagued with so much hate." This frame was used once in news coverage of the Chapel Hill shooting. Consider the following quote from The Herald-Sun,

"We are shocked that there would be anyone plagued with so much hate in their heart to execute three living human beings," the statement said ("Three young lives," 2015, p. A1).

I chose to code the phrase "plagued with so much hate" as a negative frame because of the way the frame describes the perpetrator's heart as being plagued with hatred. Therefore, the perpetrator is framed in a negative way. Further, the frame describes the 
perpetrator as hateful, therefore suggesting that the crime could be motivated by something more than parking.

The perpetrator was described as making people feel "uncomfortable" one time in news coverage. For instance, consider the following quote from the perpetrator's neighbor in The New York Times,

She said that Mr. Hicks had displayed "equal opportunity anger" and that "he kind of made everyone feel uncomfortable and unsafe" (Katz \& Paulson, 2015, p. A014).

I coded the word "uncomfortable" as a negative frame because of the obvious negative description of the perpetrator. By framing the perpetrator as an individual who made community members feel uncomfortable, news articles frame the perpetrator as behaving differently than the mainstream community, therefore framing the perpetrator as an outsider to the community.

Positive Self-Presentation

Although I captured how news coverage described the perpetrator and the victims, this section will only discuss the perpetrator. This decision was based on van Dijk's (2015) definition of positive self-presentation, which is a discursive strategy used to describe the dominant racial group in news articles. Since the perpetrator is a member of the dominant racial group, i.e. White, and the three victims were part of a minority racial group, i.e. Arabs, positive self-presentation will only be used to describe the perpetrator. Positive self-presentation frames made up 14\% of all discursive frames found in news coverage of the Chapel Hill shooting. 


\section{Figure 4.5. Number of instances of words or phrases coded as 'positive self- presentation.'}

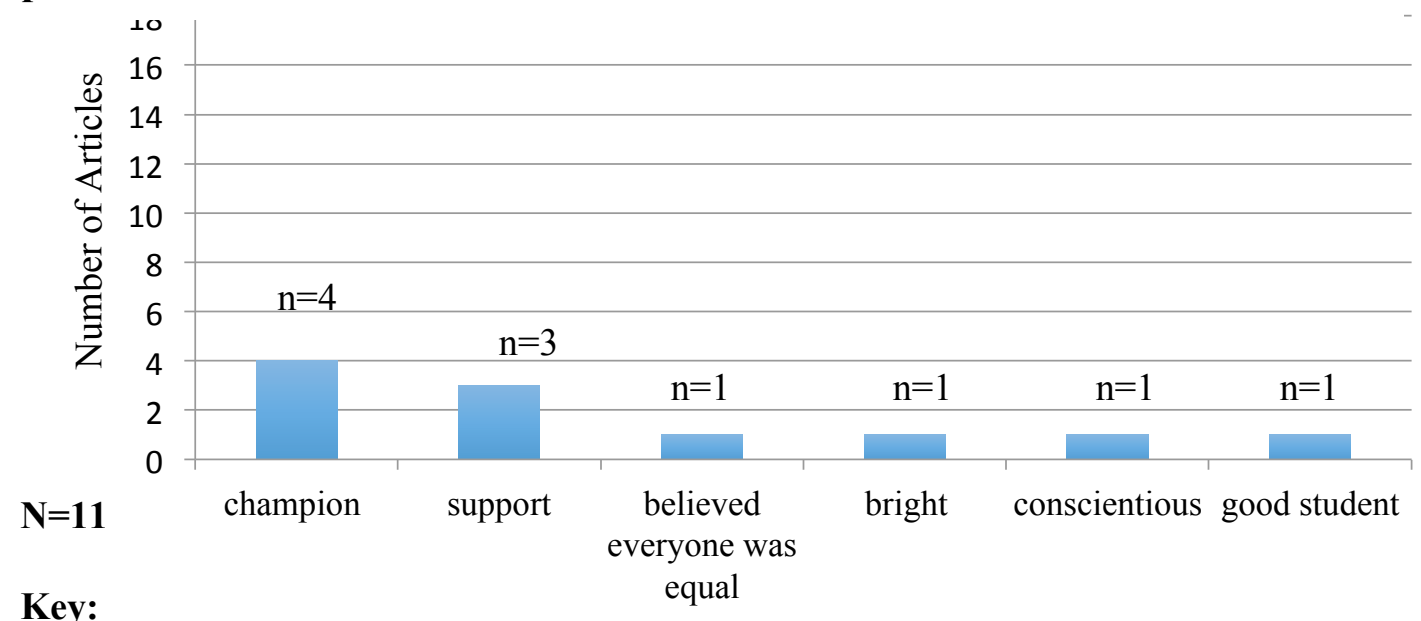

Positive Self-Presentation Words and Phrases

Figure 4.5. A chart illustrating the number of times each word or phrase was found and coded as 'positive self-presentation.'

The most frequently occurring word used to describe the perpetrator was the word "champion," which was used a total of four times. Since the frame was used similarly in each instance, I will illustrate my analysis and interpretation with one representative quote. Consider the following excerpt from The New York Times:

"He often champions, on his Facebook page, for the rights of many individuals," said Ms. Hicks, who said she had been married to Mr. Hicks for seven years" (Katz \& Paulson, 2015, p. A014).

The word "champion" was used to describe the perpetrator when illustrating his support for minority groups, and sometimes occurred more than once in a newspaper article. The word "champion" was used each time to describe the perpetrator was when describing his support for minority groups, and was primarily seen in conjunction with statements negating accusations of the perpetrator being a racist. I recognized these instances 
occurring by performing a deep reading of the articles and marking terms that framed the perpetrator in favorable terms. I chose to code the term "champion" as positive selfpresentation because it was a favorable descriptor that framed the perpetrator in a positive light. Recall that I collapsed similar words and phrases into a single subcategory. In this case, the word "champion," "champions," and "championed" were collapsed into one subcategory of the word "champion."

Another word that was used to frame the perpetrator in a positive way was "support." The frame occurred three times in news coverage. Let us examine the first instance of this frame from The New York Times,

Ms. Hicks insisted that her husband's political views showed that he was not bigoted: She has emphasized that he supports same-sex marriage, abortion rights and racial equality (Katz \& Paulson, 2015, p. A014).

The context of the word "support" was used to frame the perpetrator as supporting the rights of the LGBTQ community, abortion rights, and racial equality. Consider the following quote depicting the word "support" being used in a similar context:

His wife also pointed out his support for gay rights and the right to abortion (Katz \& Perez-Peoa, p. A01).

Descriptions of the perpetrator depicting him as a person who "supports same-sex marriage, abortion rights and racial equality" are not consistent with the character of an individual who could commit a crime based on hatred of a minority group (Katz \& Paulson, 2015, p. A014). Framing the perpetrator as an individual who supports equality for minority groups portrays the perpetrator as someone who is unlikely to commit a 
crime based on racism or discrimination. In order to justify my interpretation of this frame, I checked the context of how the frame was used. Typically, the frame of the perpetrator being a supporter of minorities was used to leaven criticism of the perpetrator being a racist or discriminatory. This frames the perpetrator as a person who does not operate under discrimination, and therefore could not have possibly been motivated by racism. Thus, racism is denied.

The third instance of the word "support" framed the perpetrator positively and was used to further exemplify the perpetrator's stance political and religious views. Consider the following quote from The Herald-Sun:

Hicks showed disdain for all faiths, but also supported a person's right to worship or not worship, legal abortion, gay marriage and the right to own and bear arms (Upchurch, 2015, p. A1).

Here, the perpetrator is framed as someone who personally does not like religion, but supported individual rights nonetheless by being described as an individual who supported people's decision on whether or not to "worship, legal abortion, gay marriage, and the right to own and bear arms." This further serves to frame the perpetrator as an individual who supports minority groups, therefore framing his character as an individual who could not be motivated by racism or discrimination.

A phrase that was used to describe the perpetrator in a positive light was "believed everyone was equal." This phrase was used once in news articles. Consider the following quote from The New York Times: 
Karen Hicks said for as long as the couple has been married Craig Hicks was a champion of individual rights. She said he believed everyone was equal ("Three young lives," 2015, p. A1).

I chose the phrase "he believed everyone was equal" as a positive self-presentation frame because it was a positive description of the perpetrator, and served to frame the perpetrator in a way that highlighted his positive attributes by depicting him as an individual who believed in equality. In the context of the sentence, the phrase was used to exemplify the perpetrator's belief of equality, and framed the perpetrator as an individual who supported individual rights. Thus, I determined that this was a positive selfpresentation frame because it was a manifest description that highlighted the perpetrator's positive attributes. Further, by describing the perpetrator's belief that everyone was equal, the description negates accusations of the perpetrator being a racist, and therefore negating accusations of the perpetrator being motivated to commit a crime because of racism or discrimination. As a result, racism is denied.

Another positive frame used to describe the perpetrator was a description of him as a student. This frame was used once. Consider the following sentence from The New York Times:

A paralegal instructor at Durham Tech, Susan Sutton, confirmed in a telephone call her previous comments to a local news media organization that Mr. Hicks was a bright, conscientious, good student, and said there had been no sign that anything was wrong (Katz \& Paulson, 2015, p. A014). 
I coded the description "bright, conscientious, good student," as three separate frames or instances that fell under the positive self-presentation discursive strategy: "bright," "conscientious," and "good student." This is because each of the three words function as a separate and definitive positive description of the perpetrator. The word "bright," is a manifest term that frames the perpetrator as a smart individual. The word "conscientious" is a manifest term that frames the perpetrator as a person who yearns to do the right thing, therefore framing the perpetrator as an individual who strives to be a good person. Finally, the description "good student" is a manifest term that describes the perpetrator as an individual who is a successful student. Overall, these words frame the perpetrator in a positive way, therefore highlighting his positive attributes, and can be used to contradict descriptions that frame the perpetrator in a negative way.

Overall, news articles utilized the discursive strategy of positive self-presentation when describing the perpetrator's character. The news articles frame the perpetrator as a person who does not match the image of a racist or bigoted individual. The quotes frame Hicks as a person who supports equality, and a "champion" of rights, and therefore frames him as an individual who does not discriminate against people because of their race or religion. These statements act as a foundation for the argument that the crime could not have been racially motivated because the perpetrator himself was not a racist. Consequently, the news media deny racism by framing the perpetrator as a person who is not a racist individual, and therefore couldn't have been motivated by racism. Thus, racism is denied. 


\section{Subtle Denials}

When describing discrimination and racism, news articles utilized subtle denials as a method to deny racism. This was achieved by inserting accusations of racism within quotation marks, which is a strategy used to suggest doubt (van Dijk, 2015). Subtle denial frames made up three percent of all discursive frames found in news coverage of the Chapel Hill shooting.

Figure 4.6. Number of instances of words or phrases coded as 'subtle denials.'

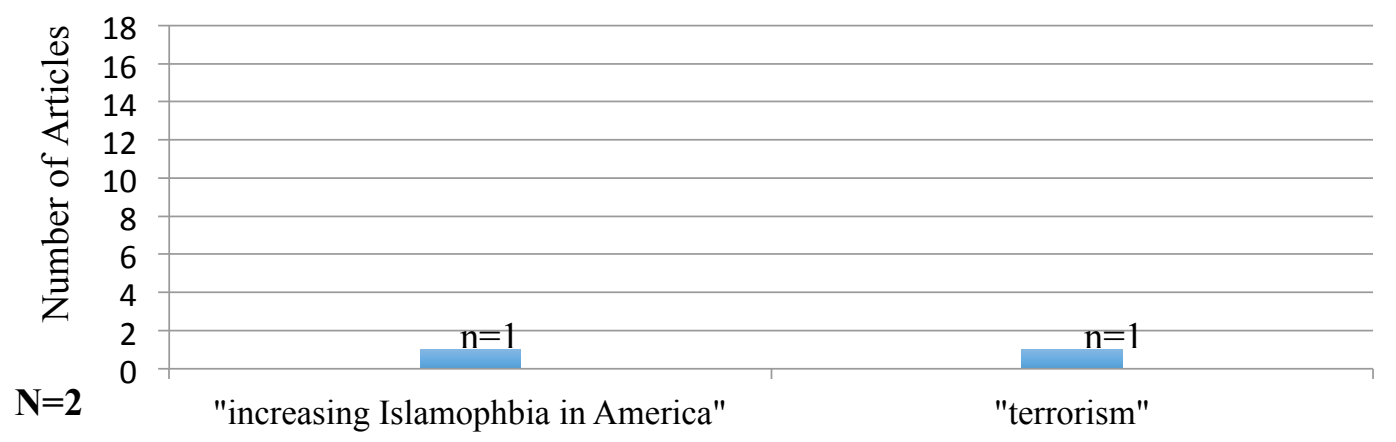

Key:

Words and Phrases

- Subtle Denials

Figure 4.6. A chart illustrating the number of times each word or phrase was found and coded as 'subtle denials.'

There were two instances of subtle denials through the use of quotation marks.

The first instance was when a news article described a statement about Islamophobia in America, which occurred once in news coverage. Consider the following quote from The Washington Post, which describes the surprise that the Chapel Hill community felt when hearing about the shooting. The community described itself as peacefully co-existing with the Muslim community for decades: 
There had been "increasing Islamophobia in America," because of the rise of the Islamic State, but he said he had seen no evidence of that in North Carolina (Sullivan \& Berman, 2015, p. A01).

The "Islamic State" refers to a terrorist organization, "Islamic State of Iraq and Syria," which had been notorious during the time of the shooting for different attacks around the world. Turn your attention to the phrase between the quotation marks, "increasing Islamophobia in America." I coded the phrase between the quotation marks as a subtle denial frame because it aligned with van Dijk's (1992) description of using quotation marks as a strategy to deny blame by framing the phrase within quotation marks as doubtful and an "unfounded accusation" (p. 185). By placing the assertion that Islamophobia has been increasing in the United States in quotation marks, the news article plants doubt in the reader about the rise of Islamophobia in the United States, thus subtly denying that Islamophobia is on the rise. By denying the rise of Islamophobia, the press can further deny that racism or Islamophobia was a motive behind the shooting. Another instance of subtle denials observed through the use of quotation marks was when an article described the crime as "terrorism." This was seen once in news coverage. Consider the following quote from The Washington Post, which illustrated the resonance of the crime to Arab and Muslim communities around the world. The quote is from the Palestinian government, which issued a statement asserting that the Chapel Hill shooting reflected "racism and religious extremism":

Reflecting global interest in the case, the Palestinian government in the West Bank on Saturday condemned the deaths as "terrorism" and called on U.S. 
authorities to include its investigators in the probe, Reuters reported (Sullivan, 2015, p. A04).

Examine the phrase between the quotation marks, "terrorism." I chose to code the phrase within quotation marks as a subtle denial frame because of the way it followed van Dijk's (1992) argument that placing accusations of racism or discrimination within quotation marks suggests doubt by framing the statement as an unfounded accusation (p. 185). By placing the assertion that the crime was an act of terrorism, the news article plants doubt in the reader about the crime being an act of terrorism, thus subtly denying that the crime was an act of terrorism. By denying the idea that the crime could be perceived as terrorism, the press can further deny that the shooting was an attack based on racism or discrimination. Thus, racism is denied.

There was one instance where I observed an accusation within quotation marks that I did not code as subtle denial. This was when an article described Hicks carrying out “execution-style" murders. Examine the following excerpt from The Washington Post:

Many said it was premature to judge before the police finish their investigation. But others said that Abu-Salha was right when he said that hate clearly motivated the "execution-style" murders (Sullivan, 2015, p. A04).

Turn your attention to the phrase between the quotation marks, "execution-style." I chose not to code the phrase between the quotation marks as a subtle denial frame because it did not interpret the phrase "execution-style" as an accusation of racism or denial.

\section{Moral Blackmail}


Throughout the descriptions examined in news coverage of the Chapel Hill shooting, there were no instances of moral blackmail recorded in the news articles.

\section{Defense and Offense}

Throughout the descriptions examined in news coverage of the Chapel Hill shooting, there were no instances of moral blackmail recorded in the news articles.

\section{Research Question 2}

Recall the second research question: In what ways does news coverage of the Chapel Hill murders compare across national and regional stories in terms of van Dijk's six discursive strategies? In order to tackle this research question, I worked from the coding scheme that I developed for the first research question, and organized each discursive frame according to whether it occurred in national or regional news coverage. I counted the occurrence of each discursive frame in national and regional coverage. I will first begin by discussing the differences across national and regional news coverage, and then discuss the similarities.

\section{Differences Across News Coverage}

The first pattern I noticed was a quantitative difference in the instances of negative self-presentation: there were more than twice as many negative self-presentation frames in national news coverage, which occurred nine times, compared to regional news coverage, which occurred four times. 


\section{Figure 4.7. Number of negative self-presentation frames in national and regional news coverage}

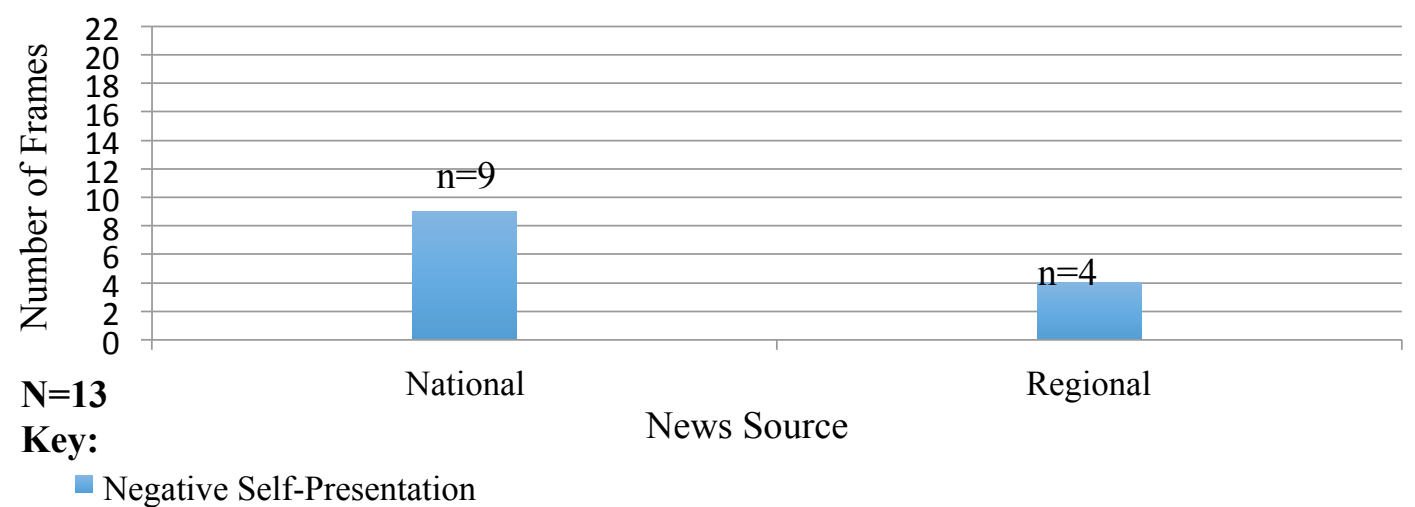

Figure 4.7. Number of negative self-presentation frames that occurred in national news coverage versus regional news coverage.

Overall, negative self-presentation was used as a tool to frame the perpetrator as an outsider to the community in national and regional news coverage. However, several differences emerged. Regional coverage focused on the victims and other neighbors, and had little to say about the perpetrator. Regional news coverage described the perpetrator's neighbors' unease with him, as well as his obsession with parking and guns, which portrayed the perpetrator as someone who did not follow the norms of the community. This ultimately frames the perpetrator as an outsider to the community, thus distancing him from society.

In contrast, national news coverage included more intimate details about the perpetrator's personality and temperament from people who were acquainted him, such as his neighbors, his ex-wife, and current wife. Neighbors typically described the perpetrator through unfavorable terms, identifying him as an angry individual who made his neighbors feel unsafe. Articles also included quotes from his ex-wife, describing the perpetrator as someone who lacked compassion, and shared an anecdote about how 
alarming it was that the perpetrator's favorite film was about an employee who was fired and retaliated by going on a shooting spree, which Hicks found to be hilarious. Negative descriptions of the perpetrator from members of the community further framed Hicks as an outsider to the community; and described him as an individual who made other members of the community feel unsafe and threatened.

A pattern arose when examining denial and counter-attack frames across national and regional news coverage. Recall that denial and counter-attack was used to present the argument that the perpetrator was motivated by a parking dispute in national and regional news coverage, thus denying the role of racism or discrimination in coverage of the Chapel Hill shooting. There was a roughly similar quantitative amount of denial and counter-attack frames used in each news source. National news coverage had ten instances of denial and counter-attack and regional had seven. However, I noticed a distinct pattern in national news coverage that was not present in regional news coverage when discussing the rationale of the crime in relation to racism.

\section{Figure 4.9. Number of denial and counter-attack frames in national and regional} news coverage

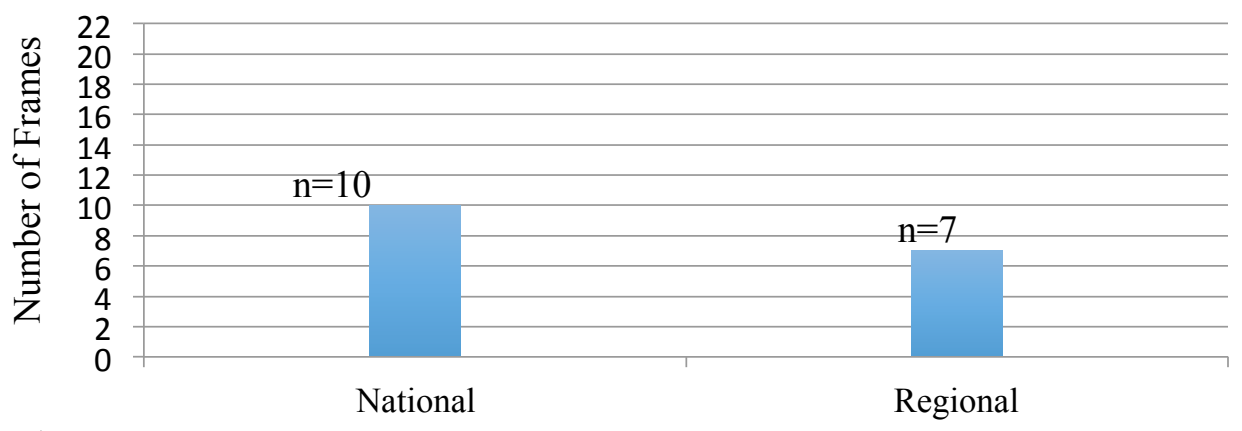

$\mathbf{N}=\mathbf{1 7}$

Key:

News Source

Denial and Counter-Attack

Figure 4.9. Number of denial and counter-attack frames that occurred in national news coverage versus regional news coverage. 
Note that both national and regional news coverage framed assertions that the shooting's rationale was a parking dispute, and used authority figures to frame those assertions as more credible. By doing so, both national and regional news coverage deny that the shooting was motivated by racism by asserting that the parking dispute was the motivation behind the shooting. However, I noticed that national news coverage included statements about the crime's possible ties to discrimination and racism, while regional news coverage did not include any content on discrimination and racism.

In particular, national news coverage included critiques of news coverage's way of framing racism and discrimination. National news articles included the Muslim community's perceptions of the coverage the crime was getting. For instance, consider the following quote from Washington Post:

"What's the difference between Charlie Hebdo and what happened here?" said Molham al-Hasni, referring to the deadly attack on a satirical newspaper by radical Islamist militants. "In Charlie Hebdo, all the presidents of the world went into the streets to march," Hasni, who said he came to the United States from Syria three years ago, said at the funeral. "When we see a Muslim killer, we say 'terrorist,' but if he's white, we say he's crazy. It's not fair”' (Sullivan, 2015, p. A04).

National news coverage included statements from the Muslim community that criticized the way the shooting and the perpetrator were covered in news media, therefore selecting more content on race and racism in national news coverage. In contrast, regional news 
coverage did not include any content on race and racism in its coverage of the Chapel Hill shooting.

\section{Similarities Across News Coverage}

I noticed a commonality across national and regional news coverage when framing the perpetrator positively. Examining the occurrences of positive selfpresentation frames in national and regional news coverage yielded roughly similar number of positive-self presentation frames used in both news sources. National news coverage framed the perpetrator positively six times, and regional news coverage five times.

\section{Figure 4.8. Number of positive self-presentation frames in national and regional news coverage}

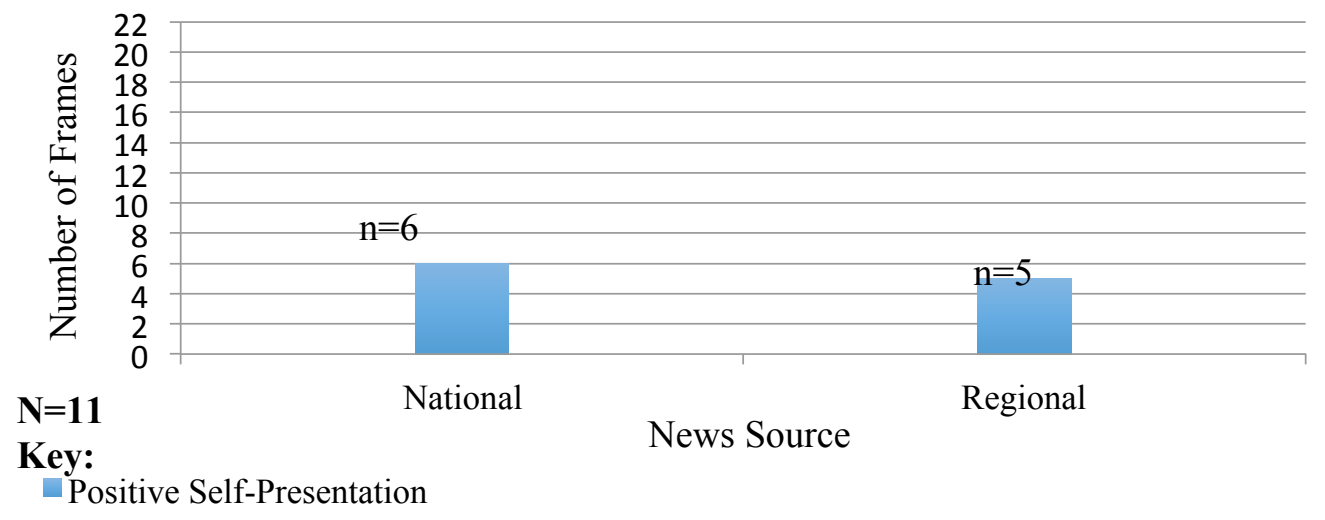

Figure 4.8. Number of positive self-presentation frames that occurred in national news coverage versus regional news coverage.

Both national and regional coverage portrayed the perpetrator as an individual who supported equality for minority groups. However, the only source of positive portrayals of the perpetrator came from his second wife. For instance, consider the quote from The New York Times: 
He often champions, on his Facebook page, for the rights of many individuals," said Ms. Hicks, who said she had been married to Mr. Hicks for seven years. "That's just one of the things I know about him, is everyone is equal," (Katz \& Paulson, 2015, p. A014).

Both national and regional news articles framed the perpetrator as a supporter of equality, thus erasing notions of the perpetrator being a racist, or being motivated by discrimination. There were no substantive differences in national and regional news coverage in the use of positive self-presentation frames of Hicks.

Another pattern I noticed was the similarity across regional and national news coverage when using the mitigations strategy. While regional news coverage had twice as many mitigation frames as national news coverage (See Figure 4.10), I noticed a similarity in the way mitigation was used to frame the crime in both news coverage sources.

Figure 4.10. Number of mitigation frames in national and regional news coverage

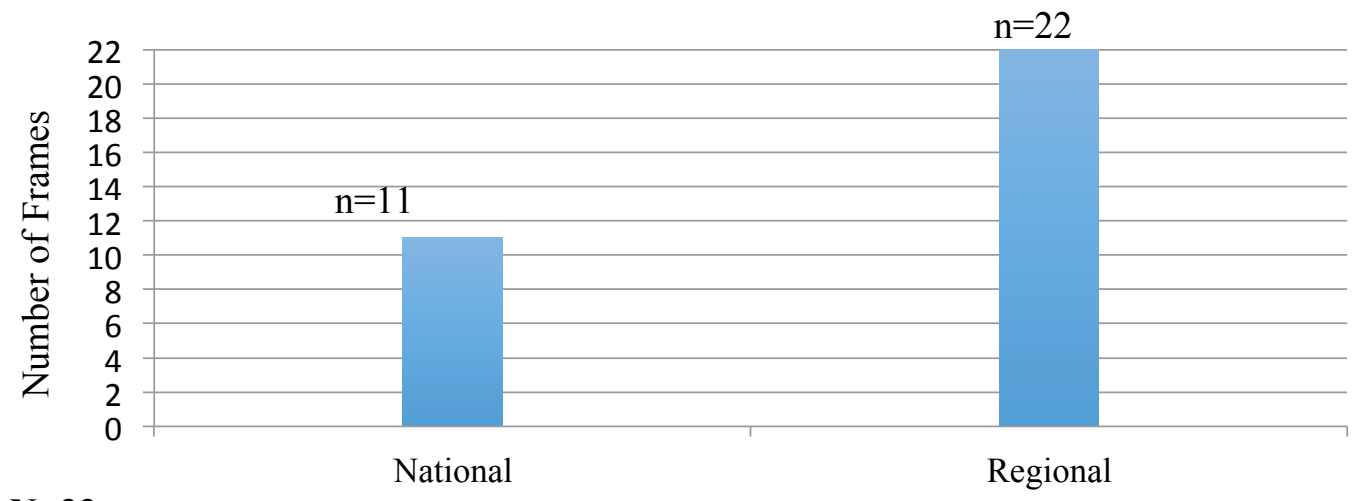
$\mathbf{N}=33$

News Source

Key: Mitigation

Figure 4.10. Number of mitigation frames that occurred in national news coverage versus regional news coverage. 
There was a substantive difference in the number of mitigation frames. Regional news coverage had 22 instances of mitigation, while national news coverage had 11.

Nonetheless, when describing the shooting, both, national and regional news coverage used mitigation similarly. They both attributed the rationale of the crime to mental health, as well as using softer euphemisms to describe the murders (i.e., using the word "event" to describe the shooting).

Subtle denial frames were not prevalent in news coverage of the Chapel Hill shooting; they were not used in regional news coverage, and were used twice in national news coverage.

\section{Figure 4.11. Number of subtle denial frames in national and regional news coverage}

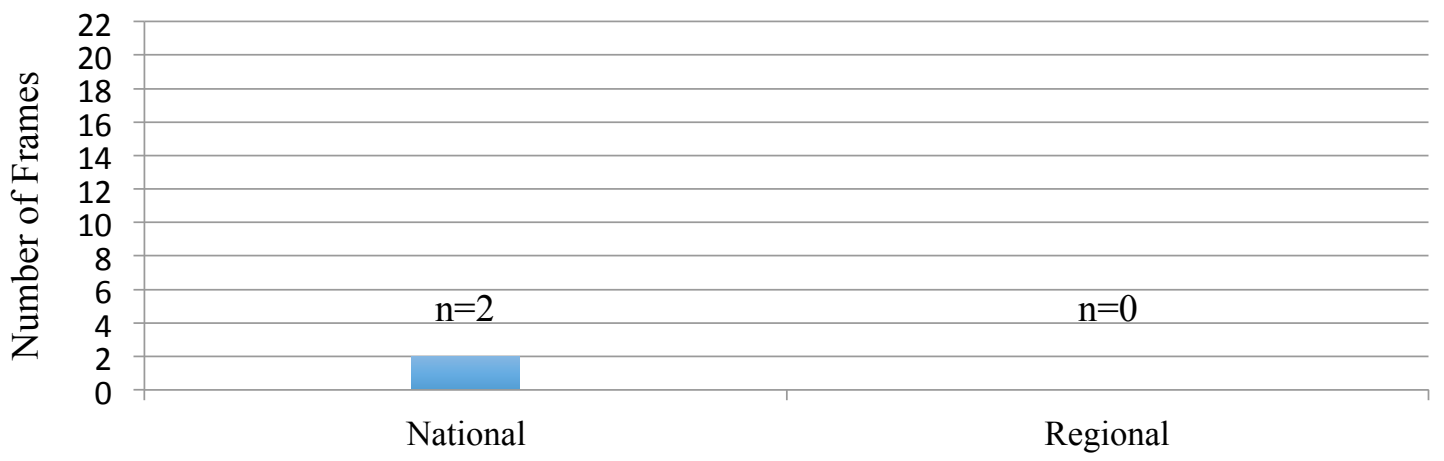

$\mathbf{N}=\mathbf{2} \quad$ News Source

Key: $\quad$ Subtle Denials

Figure 4.11. Number of subtle denial frames that occurred in national news coverage versus regional news coverage.

Essentially, subtle denial frames were used in national news coverage to deny accusations of the crime being motivated by Islamophobia or hate-related by supposing doubt in the reader through the use of quotation marks (van Dijk, 2015). Having subtle denial frames 
paired with prior arguments of a parking dispute being the shooting's rationale can undermine arguments made asserting that the shooting was motivated by racism and discrimination. However, this strategy was not widely used in either news coverage source.

There were no instances of moral blackmail or defense and offense in both, national and regional news coverage.

\section{Summary}

The overarching pattern that emerged from comparing the use of van Dijk's six discursive strategies in national and regional news coverage revealed that national news coverage included more content on race and racism. While both news sources used the denial and counter-attack strategy to frame the crime as a parking dispute, regional news coverage did not include any content discussing the possible ties of racism to the crime. In contrast, national news coverage included statements from the victims' families and members of the Muslim community asserting that the shooting was a hate crime, as well as having an entire article from Jordan dedicated to the Arab community's perception of the crime and its motivation. However, most of the content on race and racism in national news coverage was often presented with contradictory statements from figures of authority, such as policemen and lawyers, claiming that the crime was the result of a parking dispute.

Another pattern emerged when examining news coverage's description of the perpetrator. Indisputably, neither negative nor positive self-presentation discursive strategies framed the perpetrator as a racist: positive self-presentation was used to 
describe the perpetrator as a champion of equality, and negative self-presentation served to describe the perpetrator as an individual who had a bad temper. However, while I found that there were almost identical occurrences of positive self-presentation frames in national and regional news coverage, there was a substantive discrepancy in the way national and regional news coverage framed the perpetrator negatively. Regional news coverage did not use as many negative frames as national news coverage to describe the perpetrator. Moreover, regional news coverage did not include much information about the perpetrator other than information on his court hearings and verdicts. In contrast, national news coverage provided dueling narratives of the perpetrator by including more negative self-presentation frames. National news coverage provided a more rich description of the perpetrator, and included more personal information and anecdotes about the perpetrator from neighbors, his ex-wife, and current wife. These anecdotes and personal information enriched the dueling narratives of the perpetrator, framing him positively when discussing his stance on equality, and negatively when describing his character and personality. 


\section{Chapter 5: Discussion}

This chapter will discuss the significance of my findings, and comment on news coverage and racism. I will draw on critical discourse analysis to guide my interpretations on the different forms racism can take, its implications on society and how it leads to the denial of racism in news coverage. I suggest there are two gaps in van Dijk's six discursive strategies, and propose the addition of two discursive strategies that the press use to deny racism: negative self-presentation and contradiction.

\section{Implications of van Dijk's Discursive Strategies}

The presence of van Dijk's discursive strategies in news coverage of the Chapel Hill shooting revealed how racism can be questioned, framed as doubtful, and ultimately denied. Van Dijk (2015) argues that the press denies racism by using discursive strategies to make readers question accusations of racism. The discursive strategies were used as a tool to identify the denial of racism in news coverage, and point to how racism was denied in news coverage by describing the perpetrator and the shooting.

News coverage of the Chapel Hill shooting used the mitigation strategy to deny racism, and accounted for $43 \%$ of all discursive strategies used in news coverage. Mitigation attempts to alleviate racism by using softer euphemisms, such as using words like "event," or" loss," to describe the murders. This minimizes the weight of the crime by using vague terms to describe the details. News articles also reattributed the shootings to mental health and gun laws, thus framing the shooting as a result of poor societal structures rather than an individual's racist attitude. Reattributing the crime to mental health care and gun laws can shift blame away from the perpetrator and onto mental 
health and gun laws. Thus, racism is denied by leavening the weight of racist actions through euphemisms or reattribution.

Denial and counter-attack frames made up $22 \%$ of discursive strategies across news coverage of the Chapel Hill shooting. The overarching trend when describing the motivation of the murders was to deny allegations of hate, racism discrimination, and even criminal intent. This was done by directing attention to claims of the murders were the result of a parking dispute. News articles cited several sources as evidence to support claims that the shooting was motivated by a parking dispute, such as statements from the perpetrator's wife, claims from authorities that the perpetrator was obsessed with parking, statements from neighbors about Hicks's attitude towards previous parking conflicts, and quotes from law authority figures asserting that the cause of the murders was over a parking dispute. By using quotes and statements from such sources, news articles frame the cause of the shooting as a parking dispute, and denying accusations of the shooting being a hate crime.

Comparing the denial and counter attack strategy across national and regional coverage yielded an unexpected pattern: in national coverage, references to the crime as racially motivated were often paired with contradictory messages stating that the crime was motivated by a parking dispute. References to the crime being motivated by discrimination primarily came from the victims' families or members of the Muslim community, while the contradictory statements that framed the crime's rationale as a parking dispute came from law enforcement, the perpetrator's ex-wife, and the perpetrator's neighbors. For instance, refer back to the quote from The Herald-Sun: 
Officials said the preliminary motive for the killings was an ongoing neighborhood problem with parking, but family members of the victims have been calling for their deaths to be investigated as a hate crime ("Details into the investigation," 2015, p. A1).

By pairing accusations of racism with contradictory messages from figures of authority, news articles frame accusations of the crime being motivated by racism or discrimination as doubtful. However, van Dijk does not capture this strategy as a form of denial in his six discursive strategies. I postulate that there is a gap in van Dijk's discursive strategies in denying racism, and posit that the strategy of pairing contradictory statements on a racist act's rationale indicates denial of racism in news coverage. Thus, I propose another discursive strategy that denies racism: contradiction strategy.

The most interesting observation I came across in news coverage was how news coverage described the perpetrator. News coverage described the perpetrator through negative self-presentation, which accounted for $17 \%$ of discursive strategies, and positive self-presentation, which made up 14\% of discursive strategies. Findings from my second research question, which compared the differences across national and regional news coverage in its use of van Dijk's six discursive strategies, revealed a pattern of framing the perpetrator with dueling narratives. The pattern of dueling narratives was found in national news coverage, and contrasted with the way regional news coverage provided a less complex narrative of the perpetrator. The overarching theme found within the negative portrayals of the perpetrator primarily pertained to descriptions his character and personality, rather than the perpetrator's racist beliefs. For instance, the perpetrator was 
described as an individual who was threatening and lacked compassion. Negative selfpresentation was largely used to frame the perpetrator as an out-group to the community and society, and painted him as an individual who made members of the societal in-group feel uncomfortable and wary. I deemed that negative self-presentation in news coverage of the Chapel Hill shooting indicated denial of racism, because the negative portrayals focused on the perpetrator's character as a social deviant, and centered on his threatening and aggressive behavior rather than racist attitudes.

Positive self-presentation, on the other hand, provided a positive portrayal of the perpetrator by highlighting his positive attributes across national and regional news coverage (van Dijk, 2015). Whenever there were statements on the perpetrator's stance on racism, the press highlighted his beliefs on equality by framing him as an individual who "championed" for the rights of minorities. This can make it difficult to view the perpetrator as an individual who could be accused of displaying acts of racism or discrimination.

The contrasting positive and negative frames of the perpetrator in national news coverage provide a complex narrative of the perpetrator. However, these frames still stray away from attributing racist attitudes as a trait of the perpetrator. Hicks is depicted as an individual who made people feel uneasy, but also championed for the rights of minorities. Notably, neither one of these frames point to the perpetrator having a racist attitude. The positive and negative self-presentation discursive strategies worked together to deny racism by framing the perpetrator as an individual who did not have a racist attitude. In contrast to national news coverage, regional news coverage did not discuss the 
perpetrator in detail. Regional coverage had less than half of the amount of negative selfpresentation frames as national coverage, but used roughly the same amount of positive self-presentation frames. However, negative self-presentation frames in regional news coverage operated similarly to negative self-presentation in national news coverage frames: the descriptions solely focused on the perpetrator's character and personality, painting him as a social deviant and distancing him from the community. Framing the perpetrator as an outsider can make it easier to frame the crime as an isolated and abnormal act that resulted from isolated and abnormal behaviors. The scarcity of negative self-presentation frames in regional news coverage in comparison to national news coverage may be a result of regional news trying to defend Chapel Hill's reputation of not having racism within its community. Note that negative self-presentation was a discursive strategy that I introduced to the study; van Dijk does not capture a strategy that frames the perpetrator as an outsider to the community through the use of negative frames as a way of denying racism. Consequently, I suggest that negative self-presentation can be a supplement to van Dijk's six discursive strategies.

Subtle denials accounted for $2 \%$ of discursive strategies used across news coverage. Subtle denials shed doubt by prefacing accusations of racism, hate, or discrimination by inserting accusations of racism within quotation marks, which implies that the accusation is unfounded (van Dijk, 2015). For example, when an article included a description of the crime as terrorism, the word "terrorism," was placed in quotation marks. It should be noted that this strategy was not prevalent across national news coverage of the Chapel Hill shooting, and was absent in regional news coverage. I 
theorize that national coverage used subtle denials more than regional coverage because national coverage had more statements asserting that the crime was motivated by racism, therefore giving the press more opportunities to impose doubt on those statements. Regional news coverage, on the other hand, did not include statements claiming that the crime was possibly hate motivated in news articles, and therefore, had little content on accusations of racism that could be framed as unfounded and doubtful.

Notably, there were no instances of moral blackmail or defense and offense discursive strategies found across news coverage of the shooting. This was an unexpected finding, since the literature on discursive strategies and the denial of racism indicated that these six discursive strategies were commonly used by the press. I posit that further research could reveal trends in the presence of all discursive strategies and the denial of racism by examining different news stories that feature a perpetrator who is a member of a minority group, and a victim from the dominant racial group.

\section{On Racism in News Coverage}

Van Dijk (2015) argues that since the norms and laws of society prohibits overt racist behavior, members of society are sanctioned when engaging in overt displays of racism, which leads to less instances of overt racism in society. While having less overt instances of racism can lead to people believing that racism is a thing of the past, this

does not mean that racism does not exist (Tatum, 2014[1997]). Rather, racism has taken a more subtle form, making it harder to identify. Van Dijk's (2015) discursive strategies were used as a tool to identify racism, and revealed how prevalent the denial of racism is in news media. It is important to identify instances of racism and denial of racism in news 
media because it is a way of understanding the oppression that minorities face when navigating through a system designed to put minorities at a disadvantage (Tatum, 2014[1997]). For example, framing a hate crime as a parking dispute removes the narrative from minority groups of them being discriminated against. This further feeds the misconception that racism is part of the past, and is no longer an issue minority groups face. Being able to identify racism and the denial of racism in news media gives individuals the tools to combat the narrative, and perhaps influence a change in the language used in news media to describe race, racism, and its denial of racism.

Van Dijk (1992) argues that society does not want to view itself as being flawed. Shrouding racist ideology by denying it, or presenting racism subtly, like using euphemisms, mitigating instances of racism, or framing the society in a positive light, work to deny the existence of racism within society. The current study points to a salient marker of denial: regional coverage did not mention racism in any of the articles. This was an unexpected, yet significant finding. I interpreted the lack of discussion on racism as a state of denial: perhaps the community saw itself void of racism, and denying racism might be a way of protecting the community from fear of racist attacks in the future. This leads back to van Dijk's (1992) argument about how the denial of racism can lend itself to positive self-presentation by highlighting the positive attributes of society to combat accusations of racism. There are two dimensions of denial of racism, social and individual. Van Dijk argues that individuals do not like being called racist, and that extends to how the individual views racism as a societal level, using the strategy of positive self-presentation to defend the in-group as a whole. In other words, the denial 
goes from "I am not a racist," to "We are not racists," and "There is no racism in our society" (van Dijk, 1992). Regional coverage denying racism "fits" with the narrative of the community being racist-free; how could they talk about racism in their community if they don't have racism in their community to begin with? By omitting any mention of racism being a motivating factor of the shooting om regional coverage, the community could stand by its argument that the crime was simply over a parking dispute rather than being motivated by racism. This could preserve the belief that the community is racistfree.

This may explain the plethora of euphemisms used in news coverage on the whole when encountering discussions of racism. Avoiding words associated with "racist" in news media is not an uncommon phenomenon (Szychewycz, 2000; van Dijk, 1991). Mitigating and using euphemisms to describe racist acts can frame the act as an isolated crime, rather than the result of racism embedded in the society. In doing so, news coverage can frame racist acts as isolated. For example, using euphemisms like "tragic and horrific act" instead of terms such as "hate crime," or "murder," to describe the shooting shifts the attention of readers away from the idea that the basis of the problem is racism.

\section{Societal Implications}

When discussing the crime, much attention was paid to the individuals involved in the crime, rather than addressing the social structure of racism. For instance, much of the news coverage focused on the shooter's motivations. By focusing on the micro-level of why the individual was motivated, the larger implications of the crime is ignored. In 
other words, news coverage ignores the larger issues that contribute to an individual developing racist attitudes in our society. However, I acknowledge that news articles are bound by constraints, such as the time frame writers have to create the news article, limited word count, and the priority of keeping the public informed on current events, which pushes the discussion of larger implications of racist crimes in society away from the limelight. Nonetheless, this does little to address the contributing factors of racist acts and attitudes.

Tatum (2014[1997]) states that most of the information people receive about minorities do not come from first-hand experiences, but from media outlets (i.e., entertainment and news media). People typically receive partial, second-hand information about minority groups that are shaped by stereotypes. This results in individuals basing their assumptions about minorities on skewed, inaccurate, and partial information (Tatum, 2014[1997]). This could lead to people develop fear or hatred of minority groups, basing the justification of fear and hatred on inaccurate and misleading information on minority groups (Tatum, 2014[1997]). If news coverage shifted its attention onto the larger implications of racism, and how its presence in society impact its members, perhaps the narrative on race and racism could change; discourse on race and racism can work to identify the difficulties minorities face, rather than deny the existence of racism altogether.

\section{Concluding Remarks: How Does Denial of Racism Occur?}

One of the methods that the dominant group uses to maintain its racial dominance in society is the denial of racism (Hall, 2001). Racial speech is prohibited in most cultural 
norms, laws, and values, and complying members of society abide by and are aware of those social constraints. Consequently, racist behavior and speech is often met with social sanctions. In accordance with social norms surrounding racism, and mainstream society not wanting to view itself as flawed, the dominant group tends to deny accusations of racist behavior or speech (van Dijk, 2014[1992]).

Denying racism in news coverage of hate crimes is problematic because it can question the existence of racism. For instance, framing the Chapel Hill shooting as being motivated by a parking dispute frames the crime as isolated from racism, consequently denying accusations of racism and discrimination that minority groups face, and ultimately frames society as being racist-free. In other words, by denying racism in a hate crime, society can deny the existence of racism in their society; "the crime is not racist because we do not have racism in our society." Denying racism's presence in society is problematic because it denies the discrepancies of privilege and power in society, and can remove the narrative of the oppression and disadvantages that minority groups face (Tatum, 2014 [1997]).

Van Dijk (2014) argues that stereotypes are represented in the language used in news stories when discussing marginalized groups. Discourses produce and reproduce negative attitudes towards marginalized groups. Examining this from a critical discourse analysis perspective, the discourse surrounding marginalized groups does not exist to discriminate for the mere sake of discrimination. Rather, the discourse serves as broader "societal, political, and cultural functions" (van Dijk, 2014, p.425). Elite groups in politics, academia, and media have much at stake when it comes to maintaining the 
dominance of the mainstream "insider" racial group, and have the ability to control public discourse to propagate powerful persuasive measures to assert dominance over other marginalized racial groups. In other words, the dominant group has the ability to produce and reproduce racism through their control over public discourse, thus maintaining their power.

Aside from acknowledging that racism is a negative, and sometimes dangerous, attribute of society, there is a structural component to racism that makes it difficult to address and remove from society. Recall Tatum's (2014[1997]) definition of racism as “a system of advantage based on race" (p. 128). Racism is a power structure that serves to maintain the racially dominant group's expedient position over racially marginalized groups (Tatum, 2014[1997]; van Dijk, 2015). The prejudice and discrimination associated with racism extends into social structures and institutions, which marginalize minority racial groups, and benefits the dominant racial group. This is where framing comes into play; framing in news stories is tied to bias, and orients stories by accounting for "organizational and modality constraints, professional judgments, and certain judgments about the audience" (Scheufele, 1999, p. 105). Therefore, framing news stories in such a way that denies racism can influence the ideologies on race and racism in society, thus fueling behavior that is ignorant on race, racism, discriminatory behaviors, and the serious consequences of racism. Although news articles do not often discuss the larger implications of the power of language and its influence over larger societal issues in regular news stories aimed at reporting details of current events, van Dijk's (2015) discursive strategies served to indicate the persevering reach of racism's subtleties in the 
words and phrases that are selected and made salient in news coverage, and its reach on ideologies on race and racism that ultimately influence beliefs of individuals on race and racism.

\section{Limitations and Future Research}

Although there were several strides made in this research in making a conclusive argument for the denial of racism in news media, it is crucial to outline the limitations for this research. Firstly, critical discourse analysis is interpretive and explanatory (van Dijk, 2015). Researchers engaging in critical discourse analysis examine artifacts through their own interpretations and arguments. Thus, this research does not represent the entirety of newspaper discourse related to race and crime, and the results of the research can be argued against through different interpretations of the newspaper discourse analyzed. Additionally, this research limited its scope to headlines and body of text found in news articles, and excluded any images and their captions. The literature on framing race and blame in crime stories could be expanded by examining the way the victims and perpetrators are portrayed in news media through analyzing images that the news media choose to include in news articles.

Moreover, applying this research to a comparative case-study that compares two similar cases, but with the roles reversed, would make for a stronger case of the denial of racism in news media, i.e., a case where a member of a racial minority group is the perpetrator and a member of the dominant racial group is the victim, compared to a case where a member of the dominant racial group is the perpetrator and a member of a racial minority group is the victim. Doing a comparison of news coverage of the Chapel Hill 
shooting and the Charlie Hebdo attack might provide more insight on the differences of how perpetrators are framed based on their race.

Further, including a search for negative observations in news coverage would have provided more insight on what words were used compared to what words were not used. Negative comparison is a term used to refer to elements that do not occur, rather than referring to elements that do occur. In the instance of this study, searching for negative observations, such as looking for words that were not used in sentences, like "criminal" to describe the perpetrator, would provide more insight to the descriptions used to frame the Chapel Hill shooting. 


\section{References}

Anderson, K. J. (1988). Cultural hegemony and the race-definition process in Chinatown, Vancouver: 1880-1980. Environment and Planning D: Society and Space, 6(2), 127-149.

Andrews, T. (2016, May 12). George Zimmerman's many, many controversies since the Trayvon Martin case. The Washington Post. Retrieved from: https://www.washingtonpost.com/news/morning-mix/wp/2016/05/12/georgezimmermans-many-many-controversies-since-the-trayvon-martincase/?utm term=.c51ce12e33ed

Arndt, B. (2016, October 15). Rape culture hysteria on horizon for Australian universities. The Australian, p. 24.

Babb, V. (1998). Whiteness visible: The meaning of whiteness in American literature and culture. New York: New York University Press.

Bardis, P. (1979). Social interaction and social processes. Social Science, 54(3),147-167

Barnes, B., Palmary, I., \& Durrheim, K. (2001). The denial of racism the role of humor, personal experience, and self-censorship. Journal of Language and Social Psychology, 20(3), 321-338.

Bell, A. (1991). The Language of News Media. Oxford: Blackwell

Berman, G., \& Paradies, Y. (2010). Racism, disadvantage and multiculturalism: towards effective anti-racist praxis. Ethnic and Racial Studies, 33(2), 214-232.

Billig, M. (2001). Humour and hatred: The racist jokes of the Ku Klux Klan. Discourse \& Society, 12(3), 267-289. 
Bivens, D. (1995). Internalized racism: A definition. Boston: The Women's Theological Center.

Blow, C. (2012, March 16). The Curious Case of Trayvon Martin. The New York Times, p A021.

Bonilla, Y., \& Rosa, J. (2015). \# Ferguson: Digital protest, hashtag ethnography, and the racial politics of social media in the United States. American Ethnologist, 42(1), 4-17.

Burger, J. M. (2009). Replicating Milgram: Would people still obey today? American Psychologist, 64(1), 1.

Chaffee, S. (1991). Explication. Newbury Park, CA: Sage.

Chiang, S. Y. (2010). 'Well, I'ma lot of things, but I'm sure not a bigot': Positive selfpresentation in confrontational discourse on racism. Discourse \& Society, 21(3), 273-294.

Chyi, H. I., \& McCombs, M. (2004). Media salience and the process of framing: Coverage of the Columbine school shootings. Journalism \& Mass Communication Quarterly, 81(1), 22-35.

Clark, K. (1998). The linguistics of blame: Representation of women in The Sun's reporting of crimes of sexual violence. In D. Cameron (Ed.) The Feminist Critique of Language: A Reader ( $2^{\text {nd }}$ ed., pp. 183-197). London: Routledge.

Cohen, S. \& Young, J. (1981). The Manufacture of News. London: Constable.

D'angelo, P. (2002). News framing as a multiparadigmatic research program: A response to Entman. Journal of communication, 52(4), 870-888. 
Deitch, E.; Barsky, A., Butz, R., Chan, S., Brief, A \& Bradley, J. (2003). Subtle yet significant: The existence and impact of everyday racial discrimination in the workplace. Human Relations. 56(11): 1299-1324

Derry, S. (1996). Cognitive schema theory in the constructivist debate. Educational Psychologist, 31(3-4), 163-174.

Dixon, T. L. (2008). Crime news and racialized beliefs: Understanding the relationship between local news viewing and perceptions of African Americans and crime. Journal of Communication, 58(1), 106-125.

Dixon, T. L., \& Linz, D. G. (2000b). Race and the misrepresentation of victimization on local television news. Communication Research, 27, 547-573

Durrheim, K., M. Quayle, K. Whitehead and A. Kriel. 2005. Denying racism: Discursive strategies used by the South African media. Critical Arts 19(1\&2): 167-186.

Entman, R. M. (1992). Blacks in the news: Television, modern racism and cultural change. Journalism \& Mass Communication Quarterly, 69(2), 341-361.

Entman, R. M. (1993). Framing: Toward Clarification of A Fractured Paradigm. ResearchGate, 43(4), 51-58.

Entman, R. M. (1994). Representation and reality in the portrayal of blacks on network television news. Journalism \& Mass Communication Quarterly, 71(3), 509-520.

Fairclough, N. (1989). Language and Power. London: Longman.

Fairclough, N. (2013). Critical discourse analysis: The critical study of language. London: Routledge. 
Gamson, W. \& Modigliani, A. (1989). Media Discourse and Public Opinion on Nuclear Power: A Constructionist Approach. American Journal of Sociology, 95(1), p. 137.

Gilens, M. (1996). Race and poverty in America public misperceptions and the American news media. Public Opinion Quarterly, 60(4), 515-541.

Gouldner, A. W. (1976). The dialectic of ideology and technology (Vol. 976). London: Macmillan.

Graff, A. (2016, June 14). Brock Turner's ex-girlfriend defends his character: 'He never once pressured me into any situation.' San Francisco Chronicle. Retrieved from: http://www.sfgate.com/news/article/Brock-Turner-ex-girlfriend-letter-defendsupport-8136094.php

Gramsci, A. (1971). Selections from the Prison Notebooks (Q. Hoare \& G. NowellSmith, Eds., Trans.). New York: International Press.

Grubb, A. \& Turner, E. (2012). Attribution of blame in rape cases: A review of the impact of rape myth acceptance, gender role conformity and substance use on victim blaming. Aggression and Violent Behavior, 17(5), 443-452.

Hall , S. ( 1981 ). He whites of their eyes: Racist ideologies and the media. In G. Bridges \& R. Brunt (Eds.), Silver linings: Some strategies for the eighties. London, UK : Laurence and Wishart.

Hall, S. (2000). Racist ideologies and the media. Media studies: A reader, 271-282.

Hall, S. (2001). Foucault: Power, knowledge and discourse. Discourse theory and practice: A reader, $72-81$. 
Harris, F. R., \& Wilkins, R. W. (1988). Quiet Riots: Race and Poverty in the United States. The Kerner Report Twenty Years Later. Pantheon Books, Random House, Inc., 400 Hahn Road, Westminster, MD. Retrieved from http://eric.ed.gov/?id=ED310211

Healy, J. \& Lovett, I. (2015, October 3). Oregon Killer Described as Man of Few Words, Except on Topic of Guns. The New York Times, p. A1.

ICNY one of 150 Organizations to Sign Letter to U.S. Attorney General Holder Requesting Investigation of the Chapel Hill Murders | Interfaith Center of New York. (n.d.). Retrieved from http://interfaithcenter.org/icny-one-of-150organizations-to-sign-letter-to-u-s-attorney-general-holder-requestinginvestigation-of-the-chapel-hill-murders/

Jones, L. (2016). “If a Muslim says ‘homo', nothing gets done”: Racist discourse and ingroup identity construction in an LGBT youth group. Language in Society, 45(1), $113-133$.

Jonsson, P. (2012, March 24). Who is George Zimmerman, and why did he shoot Trayvon Martin? The Christian Science Monitor. Retrieved from: https://www.csmonitor.com/USA/2012/0324/Who-is-George-Zimmerman-and-whydid-he-shoot-Trayvon-Martin

KhosraviNik, M. (2010). The representation of refugees, asylum seekers and immigrants in British newspapers: A critical discourse analysis. Journal of Language and Politics, 9(1), 1-28. 
Knobel, M., \& Lankshear, C. (2007). A new literacies sampler. New York, NY: Peter Lang.

Kovel, J. (1970). White racism: A psychohistory. New York: Pantheon.

Lerner, M. \& Matthews, G. (1967). Reactions to suffering of others under conditions of indirect responsibility. Journal of personality and social psychology, 5 (3), 319 325

Lerner, M. J., \& Miller, D. T. (1978). Just world research and the attribution process: Looking back and ahead. Psychological bulletin, 85(5), 1030.

Miltner, K. M. (2014). “There's no place for lulz on LOLCats": The role of genre, gender, and group identity in the interpretation and enjoyment of an Internet meme. First Monday, 19(8).

Minsky, M. (1975). A framework for representing knowledge. In P.H. Winston (Ed.), The psychology of computer vision. New York: McGraw-Hill, 1975, pp. 211-77.

"No Mercy: Chris Harper-Mercer Told Woman to Beg for Her Life, Shot Her Anyway." (2015, October 4). Breitbart. Retrieved from: http://www.breitbart.com/biggovernment/2015/10/04/no-mercy-chris-harper-mercer-told-woman-to-beg-forher-life-shot-her-anyway/

Negative Muslim Stereotype Meme: I specialize in suicide [Digital image]. (2011). Retrieved from: http://www.quickmeme.com/meme/36bulu Negative Muslim Stereotype Meme: My wife is my property [Digital image]. (2011). Retrieved from: http://knowyourmeme.com/photos/195834-ordinary-muslim-man 
Negative Muslim Stereotype Meme: I want all Americans dead [Digital image]. (2011). Retrieved from: http://www.quickmeme.com/meme/3pghyo

Oktar, L. (2001). The ideological organization of representational processes in the presentation of us and them. Discourse \& Society, 12(3), 313-346.

Pearce, M. (2012, June 18). George Zimmerman calls show he has support -- but from whom? LA Times. Retrieved from: http://articles.latimes.com/2012/jun/18/nation/la-na-nn-who-are-georgezimmermans-supporters-20120618

Philips, M. (1984). Racist Acts and Racist Humor. Canadian Journal of Philosophy, 14(1), 75-96. Retrieved from http://www.jstor.org.proxy.lib.pdx.edu/stable/40231354

Poindexter, P. M., Smith, L., \& Heider, D. (2003). Race and ethnicity in local television news: Framing, story assignments, and source selections. Journal of Broadcasting \& Electronic Media, 47(4), 524-536.

Poole. E, \& Richardson, J. (2006). "The Effects of September 11 and the War in Iraq on British Newspaper Coverage". Muslim and the News Media, Poole Elizabeth, Richardson John E.(eds.) London: IB Tauris.

Publications.

““Racist' vigilante tried for murder.” (2013, June 26). The Daily Telegraph, p. 24. Report of the national advisory commission on civil disorders. (1968). New York: Bantam. 
Richardson, J. E. (2007). Analysing texts: Some concepts and tools of linguistic analysis. In Analyzing Newspapers: An Approach from Critical Discourse Analysis, 46-74. New York, NY: Palgrave Macmillan.

Saeed, A. (2007). Media, racism and Islamophobia: The representation of Islam and Muslims in the media. Sociology Compass, 1(2), 443-462.

Scheufele, D. A. (1999). Framing As a Theory of Media Effects. ResearchGate, 49(1), 103-122. https://doi.org/10.1111/j.1460-2466.1999.tb02784.x

Scheufele, D. A., \& Tewksbury, D. (2007). Framing, Agenda Setting, and Priming: The Evolution of Three Media Effects Models. Journal of Communication, 57(1), 920. https://doi.org/10.1111/j.0021-9916.2007.00326.x

Shaver, K. (2012). The attribution of blame: Causality, responsibility, and blameworthiness. Springer Science \& Business Media.

Small, M. L. (2009). How many cases do I need? On science and the logic of case selection in field-based research. Ethnography, 10(1), 5-38.

Szuchewycz, B. (2000). Re-pressing racism: The denial of racism in the Canadian press. Canadian Journal of Communication, 25(4).

Tatum, B. D. (2014 [1997]). Defining racism: “Can we talk?” In P. Rothenberg \& K. Mayhew (Eds.), Race, class, gender in the United States: An integrated study (pp. 125-132). New York, NY: Worth Publishers.

Teo, P. (2000). Racism in the news: A critical discourse analysis of news reporting in two Australian newspapers. Discourse \& Society, 11(1), 7-49. 
Torfing, J. (2005). Discourse theory: Achievements, arguments, and challenges. In Discourse theory in European politics (pp. 1-32). Palgrave Macmillan UK. van Dijk, T. (2014 [1992]). Discourse and the denial of racism. In A. Jaworski \& N. Coupland (Eds.), The discourse reader ( $3^{\text {rd }}$ ed., pp. 425-439). London: Routledge.

van Dijk, T. (2015). Critical discourse analysis. In D. Tannen, H. Hamilton, \& D. Schiffrin (Eds.), The Handbook of Discourse Analysis (2nd ed., Vol. 1, pp. 466485). Hoboken, NJ: John Wiley \& Son.

Van Dijk, T. A. (1983). Discourse analysis: Its development and application to the structure of news. Journal of Communication, 33(2), 20-43.

Van Dijk, T. A. (1995). Discourse analysis as ideology analysis. Language and peace, $10,47-142$.

Van Dijk, T. A. (1995). Power and the news media. Political communication and action, 9-36.

Van Dijk, T. A. (1997). The study of discourse. Discourse as structure and process, 1, 134.

van Dijk, T. A. (2015). Racism and the Press. Routledge.

van Dijk, T.A. (1992).Discourse and the denial of racism. Discourse and Society, 3, 87118.

Wasserman, H. (2010) 'We're not like that': Denial of racism in the Afrikaans press in South Africa, Communication, 36:1, 20-36, DOI: 10.1080/02500160903525015 
Whatley, M. A. (1996). Victim characteristics influencing attributions of responsibility to rape victims: A meta-analysis. Aggression and Violent Behavior, 1(2), 81-95.

Wodak, R., \& Fairclough, N. (2004). Critical discourse analysis. Qualitative Research Practice: Concise Paperback Edition, 185-202.

Yin, R.K., (1984). Case Study Research: Design and Methods. Beverly Hills, California : Sage

Zimbardo, Z. (2014). Cultural politics of humor in (de) normalizing Islamophobic stereotypes. ISJ, 2, 1 . 


\section{Appendix A: Newspaper Articles}

"Awaiting a tragedy's truth." (2015, February 13). The Herald-Sun, p. A13.

Cave, D. (2015, February 12). Outrage Over North Carolina Shootings Spurs \#MuslimLivesMatter on Twitter. The New York Times, n.p.

"Details into the investigation of the slayings." (2015, February 14). The Herald-Sun, p. A1.

Horsch, L. (2015, March 4). Triple-slaying suspect kept parking records. The HeraldSun, p. A8.

Jalabi, R. (2014, October 7). A history of Bill Maher's “not bigoted" remarks on Islam. The Guardian. Retrieved from: https://www.theguardian.com/tv-andradio/tvandradioblog/2014/oct/06/bill-maher-islam-ben-affleck

Jansen, K. (2015, March 3). DA to seek death penalty for murder suspect. The HeraldSun, p. A1.

Katz, J. . (2015, February 13). Funeral for Muslims Killed in Chapel Hill Draws Thousands. The New York Times, p. A16.

Katz, J. (2015, March 3). State to Seek Death Penalty in Killing of Students. The New York Times, p. A17.

Katz, J. (2015, March 4). In Chapel Hill, Suspect's Rage Went Beyond a Parking Dispute. The New York Times, p. A12.

Katz, J. \& Paulson, M. (2015, February 13). Accused of Murder, Remembered as Threatening. The New York Times, p. A14. 
Katz, J. \& Perez-Peoa, R. (2015, February 12). In Killing of 3 Muslims, a Question of Motive. The New York Times, p. A1.

Katz, J. \& Perez-Peoa, R. (2015, February 14). After Growing Pressure, Federal Inquiry Begins Into Muslim Students' Killings. The New York Times, p. A14.

“Killing of three Muslims spurs fear of religious bias." (2015, February 16). USA Today, p. 6A.

Morris, A. (2015, February 19). Tribute to slain; At UNCW, those of varied faiths, backgrounds gather. Star-News, p. 1A.

“Many mysteries.” (2015, February 11). Local news. The Herald-Sun, p. A1.

"NCSU scholarship to honor Chapel Hill shooting victims." (2015, February 22). StarNews, p. 22A.

"Nebraska judge blocks ban on gay union; state's attorney general appeals." (2015, March 3). The Washington Post, p. A3.

"Obama calls slayings of three Muslims in N.C. 'brutal and outrageous." (2015, February 14). The Washington Post, p. A3.

Reuters. (2015, February 17). North Carolina: Jury Brings 3 Murder Counts. The New York Times, p. A13.

“Some 5,500 people.” (2015, February 13). Local news. The Herald-Sun, p. A1.

Stanglin, D. \& Winter, M. (2015, February 12). Slain students 'loving, caring'; Authorities: Don't jump to hate crime conclusion. USA Today, p. 3A.

Sullivan, K. (2015, February 15). American Muslims cite increasing concerns about hate crimes. The Washington Post, p. A4. 
Sullivan, K. \& Berman, M. (2015, February 12). Muslims see hate behind deaths of three in N.C. The Washington Post, p. A1.

Sweis, R. (2015, February 14). Jordanians See U.S. Reporting Bias in Coverage of Student Killings. The New York Times, p. A8.

“The slayings of three college students." (2015, February 12). The Herald-Sun, p. A2.

“Three young lives were cut short.” (2015, February 12). Local news. The Herald-Sun, p. A1.

“Three people were found dead.” (2015, February 11). Local news. The Herald-Sun, p. A1.

“University leaders.” (2015, February 12). The Herald-Sun, p. A2.

Upchurch, K. (2015, February 12). Alleged Chapel hill killer denied bond. The HeraldSun, n.p.

Upchurch, K. (2015, February 17). Grand jury indicts Hicks in slaying of 3 college students. The Herald-Sun, p. A1. 
Appendix B: Framing Data

\begin{tabular}{|c|c|c|c|c|c|c|c|}
\hline & $\begin{array}{l}\text { Mitiga- } \\
\text { tion }\end{array}$ & $\begin{array}{l}\text { Denial } \\
\text { and } \\
\text { Counter } \\
\text {-Attack } \\
\end{array}$ & $\begin{array}{l}\text { Negative } \\
\text { Self- } \\
\text { Presentation }\end{array}$ & $\begin{array}{l}\text { Positive Self- } \\
\text { Presentation } \\
\end{array}$ & $\begin{array}{l}\text { Subtle } \\
\text { Denial } \\
\end{array}$ & $\begin{array}{l}\text { Moral } \\
\text { Blackmail } \\
\end{array}$ & $\begin{array}{l}\text { Defense } \\
\text { and } \\
\text { Offense } \\
\end{array}$ \\
\hline \multicolumn{8}{|c|}{ National News Coverage } \\
\hline Article 1 & - & 1 & 1 & - & - & - & - \\
\hline Article 2 & - & 1 & - & 1 & - & - & - \\
\hline Article 3 & 1 & - & - & - & - & - & - \\
\hline Article 4 & - & 1 & - & - & - & - & - \\
\hline Article 5 & - & 1 & - & - & - & - & - \\
\hline Article 6 & - & - & - & - & - & - & - \\
\hline Article 7 & - & 1 & - & - & - & - & - \\
\hline Article 8 & - & - & 8 & 5 & - & - & - \\
\hline Article 9 & 1 & - & - & - & - & - & - \\
\hline Article 10 & 3 & 2 & - & - & 1 & - & - \\
\hline Article 11 & 2 & 1 & - & - & - & - & - \\
\hline Article 12 & - & - & - & - & - & - & - \\
\hline Article 13 & - & - & - & - & - & - & - \\
\hline Article 14 & 2 & 1 & - & - & 1 & - & - \\
\hline Article 15 & 1 & 1 & - & - & - & - & - \\
\hline \multicolumn{8}{|c|}{ Regional News Coverage } \\
\hline Article 16 & - & - & - & - & - & - & - \\
\hline Article 17 & - & - & - & - & - & - & - \\
\hline Article 18 & 2 & 1 & 1 & 2 & - & - & - \\
\hline Article 19 & 11 & 1 & 2 & 2 & - & - & - \\
\hline Article 20 & 2 & 2 & - & - & - & - & - \\
\hline Article 21 & - & - & - & - & - & - & - \\
\hline Article 22 & - & - & - & - & - & - & - \\
\hline Article 23 & 1 & 1 & 1 & - & - & - & - \\
\hline Article 24 & 3 & - & - & - & - & - & - \\
\hline Article 25 & - & 1 & - & 1 & - & - & - \\
\hline Article 26 & - & - & - & - & - & - & - \\
\hline Article 27 & - & - & - & - & - & - & - \\
\hline Article 28 & 1 & - & - & - & - & - & - \\
\hline Article 29 & 3 & 1 & - & - & - & - & - \\
\hline Total & 33 & 17 & 13 & 11 & 2 & - & - \\
\hline
\end{tabular}

